\title{
La reforma financiera internacional: una agenda ampliada
}

\author{
José Antonio Ocampo \\ Secretario Ejecutivo de la \\ Comisión Económica para \\ América Latina y el Caribe
}

En este artículo se argumenta que la agenda en torno a la reforma financiera internacional debería ampliarse por lo menos en dos sentidos. En primer lugar, debería extenderse más allá de la prevención y solución de crisis financieras, para abarcar también los temas relativos al financiamiento del desarrollo de los países pobres y pequeños, y a la "propiedad" de las políticas económicas y de desarrollo por parte de los países. En segundo término, debería tener en cuenta no sólo el papel de las instituciones mundiales sino también el de las regionales y la definición explícita de las áreas en que convendría preservar la autonomía nacional. Todos estos temas deberían hacer parte de un proceso de negociación representativo y equilibrado, capaz de superar algunos de los aspectos negativos, vinculados a la economía política, que caracterizan al debate actual. Después de un análisis preliminar de la naturaleza de los problemas que enfrenta el sistema vigente y de algunos aspectos de la economía política, se examinan los siguientes temas: i) las reformas relacionadas con la prevención y solución de crisis financieras; ii) la función del financiamiento del desarrollo, incluido el papel que puede desempeñar el financiamiento multilateral para contribuir a la mayor participación de los países de bajos ingresos y los países pequeños de medianos ingresos en los mercados privados de capital, y el financiamiento de redes de seguridad social en períodos de crisis; iii) la necesidad de concertar un nuevo acuerdo internacional sobre los límites de la condicionalidad y el pleno reconocimiento del papel central de la "propiedad" de las políticas macroeconómicas y de desarrollo por parte de los países en desarrollo; iv) la contribución de las instituciones regionales y subregionales a la mayor provisión de "bienes públicos globales" y otros servicios en el área de las finanzas internacionales; y v) la necesidad de preservar la autonomía nacional en diversos campos, incluidas la regulación de la cuenta de capitales y la elección del régimen cambiario. En el artículo se afirma que las instituciones regionales y la autonomía nacional revisten particular importancia para los participantes menos influyentes en el ámbito internacional, que se beneficiarían notablemente de la competencia en los servicios que se les prestan y la conservación de la libertad de acción en un contexto de provisión imperfecta de bienes públicos globales. 


\section{I}

\section{Introducción}

El período reciente de inestabilidad financiera que tras iniciarse en Asia se extendió a Rusia y terminó contagiando a América Latina, generó un profundo convencimiento de que se requiere una reforma profunda de la arquitectura financiera internacional, con el fin de prevenir nuevas crisis financieras y responder a ellas en forma más adecuada. La crisis condujo, en efecto, al reconocimiento de que existe una enorme discrepancia entre un mercado financiero cada vez más sofisticado y dinámico, pero inestable, y las instituciones que lo regulan, de que "las instituciones actuales no son las adecuadas para enfrentar la globalización financiera". ${ }^{1}$

La crisis desencadenó respuestas positivas: un esfuerzo expansionista concertado, liderado por los Estados Unidos, que probablemente contribuyó más que ningún otro factor a la normalización de los mercados de capitales, relativamente rápida aunque incompleta; la aprobación de nuevas líneas de crédito y el incremento de los recursos del Fondo Monetario Internacional (FMI); el reconocimiento de la necesidad de crear incentivos para inducir perfiles adecuados de endeudamiento de los países en desarrollo; el impulso especial dado a las actividades internacionales destinadas a establecer estándares mínimos de regulación y supervisión prudencial, así como de información; la aceptación parcial por parte del Fondo de que la imposición de exigencias exageradas en el ámbito fiscal es inadecuada en los programas de ajuste; el perfeccio-

Este artículo se basa en parte en el Informe del Grupo de Trabajo del Comité Ejecutivo de Asuntos Económicos y Sociales de las Naciones Unidas (Naciones Unidas, Grupo de Trabajo, 1999a), que el autor coordinó, así como en dos ensayos posteriores (Ocampo, 1999a y 1999b) y en un trabajo realizado conjuntamente con Stephany Griffith-Jones (Griffith-Jones y Ocampo, 1999) con el apoyo del Ministerio de Relaciones Exteriores de Suecia. Los debates que tuvieron lugar en la reunión del Centro Internacional de Investigaciones para el Desarrollo (CID), celebrada en Ottawa (Canadá), preparatoria de un proyecto de amplio alcance sobre reforma del sistema financiero internacional, sirvieron para esclarecer algunos de los temas que se examinan en el presente documento. El autor agradece a Oscar Altimir, Reynaldo Bajraj, Nicolás Eyzaguirre, Gunther Held, Gerald K. Helleiner y los participantes en el taller sobre la Autoridad Financiera Mundial celebrado en la New School for Social Research de Nueva York, por sus comentarios sobre un borrador de este trabajo, y a Guillermo Mundt y Camilo Tovar por la elaboración de los datos que se presentan en la sección I.

${ }^{1}$ Naciones Unidas, Grupo de Trabajo del Comité Ejecutivo de Asuntos Económicos y Sociales (1999a, sección I). namiento de la Iniciativa para los Países Pobres muy Endeudados; y la mayor importancia otorgada al diseño de redes apropiadas de protección social en los países en desarrollo. Algunas de las respuestas fueron positivas, pero al parecer no tienen una orientación bien definida (o tienen incluso una dirección inadecuada). Tal es el caso de la adopción de cláusulas de acción colectiva en las emisiones de títulos de deuda externa, como elemento esencial para facilitar la suspensión de los pagos con anuencia internacional y la renegociación ordenada de la deuda en condiciones críticas. En algunos casos, las respuestas fueron insuficientes o abiertamente inadecuadas: la condicionalidad del FMI se tornó excesiva; no se ha prestado la debida atención al diseño de esquemas sólidos que permitan una mayor coherencia de las políticas macroeconómicas de los países industrializados; la propuesta japonesa de crear un Fondo Monetario Asiático despertó una fuerte e inmerecida oposición, que obligó a desecharla rápidamente; en términos más generales, no se ha dado suficiente consideración al papel que pueden desempeñar las instituciones regionales en el establecimiento de un sistema financiero internacional más adecuado; y no se han tomado medidas encaminadas a dar la representación que les corresponde a los países en desarrollo en el debate sobre la reforma o en la concepción de una nueva arquitectura financiera internacional.

La normalización relativamente rápida de los mercados de capitales parece haber provocado una actitud de complacencia que podría frenar el proceso de reforma. Además, podría orientar la discusión en una dirección inadecuada. Tal sería el caso de reabrir el debate sobre la convertibilidad de la cuenta de capitales. Por el contrario, las condiciones más estables podrían utilizarse como una posibilidad de ampliar la agenda, y dar inicio a un proceso de negociaciones representativo y equilibrado. Esta ampliación de la agenda debería darse al menos en dos sentidos: en primer lugar, extendiéndola fuera del ámbito de la prevención y solución de crisis financieras (es decir, de lo que podría definirse como arquitectura financiera en un sentido "restringido") ${ }^{2}$ para incluir temas tales como el financiamiento del desarrollo y la "propie-

\footnotetext{
2 Ocampo (1999a).
} 
dad" de las políticas económicas y, sobre todo, de las políticas de desarrollo, por parte de los países; en segundo término, tomando en consideración en forma sistemática no sólo el papel de las instituciones de carácter mundial, sino también de las regionales y aquellas áreas en que debería mantenerse la autonomía nacional. Estos son los temas en que se centra este estudio. En las dos secciones siguientes se presenta una breve reflexión sobre la naturaleza de los problemas que enfrenta el sistema y la economía política del proceso de reforma. A continuación, se analizan la prevención y el manejo de crisis, el financiamiento del desarrollo, el tema de la condicionalidad por contraposición a la "propiedad" de las políticas, que se aplica a ambos, la función de las instituciones regionales, y la autonomía y las regulaciones nacionales.

\section{II}

\section{Naturaleza de los problemas que enfrenta el sistema}

En la década actual, los flujos internacionales de capital dirigidos a los países en desarrollo han tenido cuatro características sobresalientes. ${ }^{3}$ En primer lugar, los flujos de capital oficial y privado han mostrado tendencias divergentes: mientras los primeros han tendido a disminuir, las corrientes de capital privado han experimentado un fuerte incremento a mediano plazo. En segundo término, los distintos tipos de flujos de capital privado han manifestado diferencias notorias en términos de su estabilidad. En tercer lugar, los flujos privados se han concentrado en los países de ingreso medio; esta tendencia sólo ha sido compensada parcialmente por el papel redistributivo que han generado los flujos oficiales a nivel mundial. Por último, la inestabilidad de los flujos de capital privado ha impuesto la necesidad de diseñar importantes programas de rescate, de magnitudes sin precedentes, que han concentrado los fondos en unas pocas economías emergentes de gran tamaño.

El cuadro 1 ilustra las dos primeras tendencias. Tanto la inversión extranjera directa (IED) como los flujos financieros privados de toda índole han experimentado un crecimiento importante a mediano plazo. Sin embargo, estos flujos presentan profundas diferencias en términos de estabilidad: mientras la IED se ha mantenido relativamente inalterable durante las crisis, los flujos financieros privados han mostrado una marcada volatilidad y efectos de "contagio". Por su parte, en contraste con el dinamismo de los flujos privados, el financiamiento oficial para el desarrollo, sobre todo

\footnotetext{
${ }^{3}$ Véase UNCTAD (1999, capítulos III y V), y Banco Mundial (1999), en los que se presenta un análisis detallado de estas tendencias.
}

su principal componente, los fondos de asistencia bilateral, ha tenido una evolución poco satisfactoria. De hecho, la asistencia bilateral ha disminuido en términos reales a lo largo de la década y se estima que en 1998 representó el $0.22 \%$ del PIB de los países industrializados, una reducción muy acentuada con respecto al $0.35 \%$ del PIB registrado a mediados de los años ochenta. ${ }^{4}$ La disminución de la asistencia bilateral ha sido más notoria en el caso de los países industrializados más grandes, pero ha sido compensada en parte, en términos de transferencia efectiva de recursos, por la creciente participación de las donaciones en la ayuda bilateral. Por otra parte, en contra de lo que ha sido característico de los flujos privados, el financiamiento oficial no ha sido procíclico $y$, de hecho, algunos de sus componentes - en particular, los apoyos para balanza de pagos, pero también el financiamiento multilateral para el desarrollo- han experimentado un comportamiento anticíclico.

La tercera tendencia se observa en el cuadro 2. Los flujos privados se han concentrado en los países de ingreso medio. Por el contrario, la proporción de financiamiento privado destinado a países de bajos ingresos ha sido inferior no sólo a su participación en la población total de los países en desarrollo, lo cual es esperable, sino también al PIB de dichos países. Esta situación es aún más marcada en el caso de las emisiones de bonos, del financiamiento de la banca comercial y de los flujos de capital accionario, si se exceptúa a la India en este último caso. En todos estos ca-

\footnotetext{
${ }^{4}$ Banco Mundial (1999, cap. 4, p. 70).
} 
Flujo neto de recursos a largo plazo hacia los países en desarrollo, ${ }^{a}$ 1990-1998 (Miles de millones de dólares)

\begin{tabular}{|c|c|c|c|c|c|c|c|c|c|}
\hline & 1990 & 1991 & 1992 & 1993 & 1994 & 1995 & 1996 & 1997 & $1998^{\mathrm{b}}$ \\
\hline Flujo neto de recursos a largo plazo & 100,8 & 123,1 & 152,3 & 220,2 & 223,6 & 254,9 & 308,1 & 338,1 & 275,0 \\
\hline Oficiales & 56,9 & 62,6 & 54,0 & 53,3 & 45,5 & 53,4 & 32,2 & 39,1 & 47,9 \\
\hline Privados & 43,9 & 60,5 & 98,3 & 167,0 & 178,1 & 201,5 & 275,9 & 299,0 & 227,1 \\
\hline De mercados internacionales de capital & 19,4 & 26,2 & 52,2 & 100,0 & 89,6 & 96,1 & 149,5 & 135,5 & 72,1 \\
\hline Deuda privada & 15,7 & 18,6 & 38,1 & 49,0 & 54,4 & 60,0 & 100,3 & 105,3 & 58,0 \\
\hline Bancos comerciales & 3,2 & 4,8 & 16,3 & 3,3 & 13,9 & 32,4 & 43,7 & 60,1 & 25,1 \\
\hline Bonos & 1,2 & 10,8 & 11,1 & 37,0 & 36,7 & 26,6 & 53,5 & 42,6 & 30,2 \\
\hline Otros & 11,4 & 3,0 & 10,7 & 8,6 & 3,7 & 1,0 & 3,0 & 2,6 & 2,7 \\
\hline Capital accionario & 3,7 & 7,6 & 14,1 & 51,0 & 35,2 & 36,1 & 49,2 & 30,2 & 14,1 \\
\hline Inversión extranjera directa & 24,5 & 34,4 & 46,1 & 67,0 & 88,5 & 105,4 & 126,4 & 163,4 & 155,0 \\
\hline
\end{tabular}

Fuente: Banco Mundial, Global Development Finance, 1999, Washington, D.C., marzo de 1999.

a El flujo neto de recursos a largo plazo se define como transacciones netas de pasivos con un vencimiento original superior a un año. Aunque la República de Corea es un país de altos ingresos, se le incluye en la categoría de países en desarrollo por ser deudor del Banco Mundial.

b Datos preliminares.

sos, el financiamiento de origen privado a los países pobres es mínimo. La proporción de IED captada por los países de bajos ingresos también es inferior a su contribución al PIB de los países en desarrollo. Otra característica destacada de la IED es su alta concentración en la China, país que, sin embargo, recibe una proporción menor de flujos financieros. Debido a la alta concentración de los flujos más volátiles en los países de ingreso medio, con la excepción de China, los temas de la volatilidad de los flujos de capital y los fenómenos de contagio han adquirido particular importancia para ellos.

Por lo tanto, los países de bajos ingresos han quedado al margen de los flujos privados y han seguido dependiendo de las fuentes oficiales de recursos, cada vez más limitadas. Más específicamente, han sido muy dependientes de la asistencia oficial para el desarrollo, especialmente de donaciones, correspondiente en su mayor parte a asistencia bilateral. Si también se excluye a la India en este caso, éste es el único componente de los flujos netos de recursos destinados a los países en desarrollo que está distribuido en forma progresiva, en el sentido de que la proporción recibida por países de bajos ingresos no sólo supera su participación en el PIB de dichos países, sino asimismo en la población. Este patrón también caracteriza al financiamiento multilateral, con la excepción de aquel proveniente del Fondo Monetario Internacional.

La volatilidad de los flujos financieros privados, por una parte, y su fuerte concentración en los países de ingreso medio, por otra, han terminado generando necesidades de financiamiento excepcional de magnitudes sin precedentes, que se ha concentrado en unas pocas economías emergentes. Como consecuencia de ello, el financiamiento del Fondo Monetario, incluido el del servicio financiero reforzado de ajuste estructural, ha presentado una marcada trayectoria anticíclica en relación con los flujos privados y una concentración en un escaso número de países. Como se observa en el gráfico 1, ambas tendencias están estrechamente relacionadas, ya que el endeudamiento cíclico de unos pocos países es el principal factor determinante del patrón cíclico general. Esta última característica se ha intensificado en los últimos años. Por lo tanto, mientras la India y los tres mayores prestatarios latinoamericanos recibieron menos de la mitad de los flujos reales netos provenientes del Fondo Monetario en el período 1980-1984, los correspondientes a sólo cuatro de los principales prestatarios (Indonesia, la República de Corea, la Federación Rusa y México) superaron por un leve margen los flujos reales totales otorgados por el Fondo en 1995-1997. Por consiguiente, la proporción del financiamiento del Fondo destinado a grandes prestatarios ${ }^{5}$ ha presentado una acentuada tendencia al alza en las dos últimas décadas. De hecho, en los datos sobre financiamiento del Fondo Monetario en los últi-

\footnotetext{
${ }^{5}$ Este grupo está integrado por Argentina, Brasil, China, la Federación Rusa, Indonesia, India, México y la República de Corea.
} 
Flujo neto de recursos, 1992-1997

(Promedios anuales, en miles de millones de dólares y porcentajes)

\begin{tabular}{|c|c|c|c|c|c|c|c|c|c|c|}
\hline & \multicolumn{2}{|c|}{$\begin{array}{c}\text { Inversión extranjera } \\
\text { directa }\end{array}$} & \multicolumn{2}{|c|}{$\begin{array}{l}\text { Flujo de capital } \\
\text { accionario }\end{array}$} & \multicolumn{2}{|c|}{ Donaciones } & \multicolumn{2}{|c|}{$\begin{array}{c}\text { Financiamiento } \\
\text { bilateral }\end{array}$} & \multicolumn{2}{|c|}{$\begin{array}{c}\text { Financiamiento multilateral } \\
\text { (excepto del FMI) }\end{array}$} \\
\hline & Monto & Porcentaje & Monto & Porcentaje & Monto & Porcentaje & Monto & Porcentaje & Monto & Porcentaje \\
\hline Países en desarrollo & 99.0 & 100.0 & 35.7 & 100.0 & 29.7 & 100.0 & 2.9 & 100.0 & 13.7 & 100.0 \\
\hline Excepto China & 66.8 & 67.5 & 31.7 & 88.9 & 29.4 & 99.0 & 0.5 & 19.0 & 11.6 & 84.5 \\
\hline Países de bajos ingresos & 6.7 & 6.8 & 3.4 & 9.5 & 15.8 & 53.2 & 0.8 & 27.1 & 5.9 & 43.4 \\
\hline India & 1.6 & 1.6 & 2.5 & 6.9 & 0.6 & 1.9 & -0.3 & -11.3 & 1.0 & 7.4 \\
\hline Otros & 5.1 & 5.2 & 0.9 & 2.6 & 15.2 & 51.3 & 1.1 & 38.4 & 4.9 & 36.0 \\
\hline China $^{a}$ & 32.1 & 32.5 & 3.9 & 11.1 & 0.3 & 1.0 & 2.3 & 81.0 & 2.1 & 15.5 \\
\hline Países de medianos ingresos & 60.1 & 60.8 & 28.3 & 79.4 & 13.7 & 46.1 & -0.2 & -8.1 & 5.6 & 41.1 \\
\hline Argentina & 4.4 & 4.5 & 1.7 & 4.9 & - & 0.1 & -0.1 & -3.2 & 0.9 & 6.6 \\
\hline Brasil & 7.7 & 7.7 & 4.1 & 11.5 & 0.1 & 0.2 & -1.3 & -43.4 & -0.1 & -0.6 \\
\hline Federación Rusa & 1.9 & 1.9 & 1.1 & 3.1 & 1.1 & 3.7 & 0.6 & 21.4 & 0.9 & 6.2 \\
\hline Indonesia & 3.5 & 3.6 & 2.4 & 6.8 & 0.2 & 0.8 & 1.2 & 41.7 & 0.1 & 0.9 \\
\hline República de Corea ${ }^{b}$ & 1.5 & 1.5 & 3.1 & 8.8 & - & - & -0.2 & -5.4 & 0.6 & 4.1 \\
\hline México & 8.1 & 8.2 & 5.1 & 14.3 & - & 0.1 & -0.6 & -21.4 & 0.3 & 2.2 \\
\hline \multirow[t]{3}{*}{ Otros } & 33.0 & 33.3 & 10.7 & 30.1 & 12.2 & 41.2 & 0.1 & 2.2 & 3.0 & 21.7 \\
\hline & \multicolumn{2}{|c|}{ Bonos } & \multicolumn{2}{|c|}{$\begin{array}{c}\text { Préstamos de bancos } \\
\text { comerciales }\end{array}$} & \multicolumn{2}{|c|}{ Otros préstamos } & \multicolumn{2}{|c|}{ Total } & \multicolumn{2}{|l|}{ Memo: } \\
\hline & Monto & Porcentaje & Monto & Porcentaje & Monto & Porcentaje & Monto & Porcentaje & PIB & Población \\
\hline Países en desarrollo & 34.6 & 100.0 & 28.3 & 100.0 & 4.9 & 100.0 & 248.7 & 100.0 & 100.0 & 100.0 \\
\hline Excepto China & 32.9 & 95.2 & 26.6 & 94.0 & 1.1 & 21.4 & 200.7 & 80.7 & 89.2 & 74.8 \\
\hline Países de bajos ingresos & 0.5 & 1.5 & 0.9 & 3.3 & 0.4 & 7.2 & 34.5 & 13.9 & 11.4 & 41.0 \\
\hline India & 0.4 & 1.1 & 0.8 & 2.8 & 0.4 & 8.9 & 6.9 & 2.8 & 5.6 & 19.3 \\
\hline Otros & 0.2 & 0.4 & 0.2 & 0.6 & -0.1 & -1.7 & 27.6 & 11.1 & 5.8 & 21.7 \\
\hline China $^{a}$ & 1.7 & 4.8 & 1.7 & 6.0 & 3.9 & 78.6 & 48.0 & 19.3 & 10.8 & 25.2 \\
\hline Países de medianos ingresos & 32.4 & 93.7 & 25.7 & 90.7 & 0.7 & 14.2 & 166.3 & 66.9 & 77.8 & 33.9 \\
\hline Argentina & 5.5 & 15.9 & 0.8 & 2.9 & - & -0.9 & 13.3 & 5.3 & 5.0 & 0.7 \\
\hline Brasil & 3.1 & 9.0 & 8.2 & 29.0 & -0.6 & -11.3 & 21.2 & 8.5 & 10.5 & 3.3 \\
\hline Federación Rusa & 0.8 & 2.2 & 0.3 & 1.1 & 1.4 & 28.7 & 8.1 & 3.2 & 7.3 & 3.1 \\
\hline Indonesia & 1.6 & 4.7 & 0.9 & 3.2 & 0.2 & 3.7 & 10.2 & 4.1 & 3.4 & 4.0 \\
\hline República de Coreab & 4.5 & 12.9 & 4.1 & 14.5 & -0.2 & -4.8 & 13.4 & 5.4 & 7.3 & 0.9 \\
\hline México & 5.2 & 15.2 & 0.3 & 1.1 & -0.3 & -6.9 & 18.2 & 7.3 & 6.7 & 1.9 \\
\hline Otros & 11.7 & 33.8 & 11.0 & 38.9 & 0.3 & 5.6 & 81.9 & 32.9 & 37.6 & 19.8 \\
\hline
\end{tabular}

Fuente: Banco Mundial, Global Development Finance, 1999, Washington, D.C., marzo de 1999 y World Economic Indicators, Washington, D.C., 1998, en lo que respecta a los datos sobre el PIB y población.

a El Banco Mundial consideró a China un país de bajos ingresos hasta 1998. A partir de 1999 se lo incluye entre los países de medianos ingresos. En el presente cuadro aparece en una categoría separada.

b El Banco Mundial lo considera un país de altos ingresos, pero en Global Development Finance, 1999 se lo incluye en la categoría de países de medianos ingresos.

mos años, la provisión de fondos de emergencia a grandes receptores está subestimada, debido a que no se incluyen las contribuciones bilaterales a los programas de rescate de seis países (Indonesia, la República de Corea, Tailandia, la Federación Rusa, Brasil y México). ${ }^{6}$

\footnotetext{
${ }^{6}$ Sin embargo, cabe insistir en que, en los programas de rescate, los préstamos bilaterales comprometidos suelen desembolsarse en proporciones menores que los fondos multilaterales correspondientes.
}

En un sentido estricto, sin embargo, no se ha producido un desplazamiento de los pequeños por los grandes prestatarios, dado que el financiamiento global del Fondo ha respondido con elasticidad a la demanda de los países grandes, pero aquel destinado a otros países, pobres o pequeños de ingreso medio, ha seguido mostrando una cierta estabilidad o incluso un leve aumento cuando dichos países han requerido apoyo adicional de balanza de pagos. Eso es lo que aconteció en la década de 1980 en la mayoría de los países en desarrollo y lo que ha sucedido en el caso de la pro- 
GRAFICO

Uso de los créditos del Fondo Monetario Internacional, 1970-1997
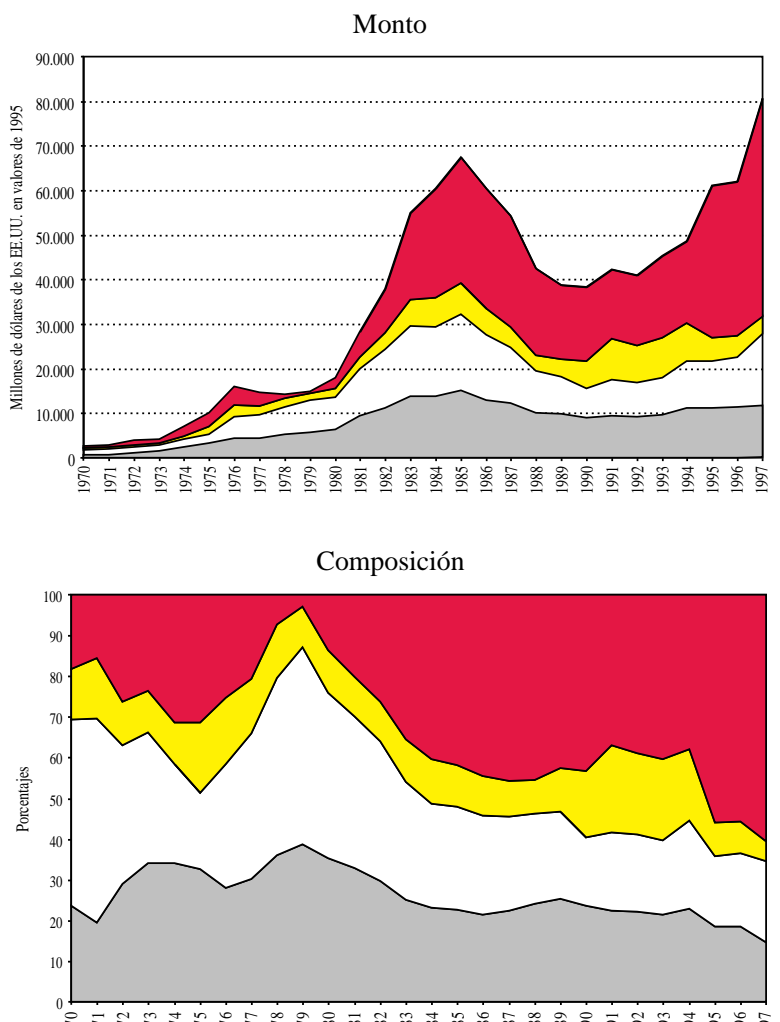

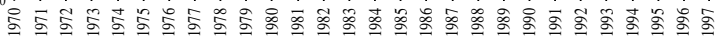

\begin{tabular}{|lc|}
\hline$\square$ Países de bajos ingresos, excepto India & $\square$ Países de medianos ingresos bajos, \\
excepto China, Rusia e Indonesia \\
$\begin{array}{l}\text { Países de medianos ingresos altos, excepto } \\
\text { Argentina, Brasil y México }\end{array}$ \\
\hline Grandes deudores \\
\hline
\end{tabular}

visión de fondos a los países medianos de Asia-Pacífico en los últimos años. De todos modos, el financiamiento del Fondo y el financiamiento bilateral de contrapartida con fines de liquidez han sido complementarios de los fondos privados a lo largo del ciclo económico. Dada la alta concentración del financiamiento de origen privado en países de ingresos medios, esto ha dado lugar a un patrón similar de concentración en el caso del financiamiento oficial de liquidez. En un contexto de notable escasez de financiamiento oficial para países de bajos ingresos, la acentuada concentración de la asistencia para balanza de pagos en unas pocas economías emergentes plantea grandes interrogantes con respecto a la racionalidad global que rige la distribución de los flujos mundiales de capital, incluidos los oficiales. Ciertamente, lleva a cuestionar si la respuesta de la comunidad internacional está sesgada por los problemas de los países en desarrollo más grandes.

Así las cosas, aunque la volatilidad y el contagio que muestran los flujos de capital privado, temas que han acaparado la atención en el debate reciente, son indudablemente problemáticos, hay otros problemas de igual importancia, como la marginalización de los países más pobres de los flujos de capital privado y la reducción de la asistencia bilateral de la que dependen en gran medida. La reforma de la estructura financiera internacional debería ofrecer, por lo tanto, soluciones a todos estos problemas. Además, la excesiva deuda de muchos países en desarrollo, sobre todo de los más pobres, sigue limitando notablemente sus posibilidades de desarrollo.

\section{III}

\section{Algunas reflexiones sobre la economía política del proceso de reforma}

La naturaleza de la actual controversia sobre la reforma del sistema financiero internacional refleja tres características de la economía política del proceso de globalización en marcha. La primera es la resistencia de la mayoría de los países, tanto industrializados como en desarrollo, a ceder su soberanía económica a organizaciones internacionales. Ante la influencia de las poderosas fuerzas del mercado características de la globalización, que tienden a debilitar a los Estados nación, y los procesos unilaterales de liberalización que han adoptado muchos países en forma simultánea, las regulaciones gubernamentales han perdido terreno en todo el mundo. A juicio de muchos analistas, esto puede considerarse como un avance, pero también es fuente de graves riesgos y distorsiones. De hecho, los temas relacionados con los flujos de capital que se analizan en la sección IV son un buen ejemplo de casos en los cuales la mayoría de los analistas considera que la regulación inadecuada, tanto nacional como internacional, ha sido un importante determinante de 
la inestabilidad del mercado. Otro ejemplo digno de mención es el de las normas sobre "prácticas comerciales desleales", como las reglas antidumping y los derechos compensatorios que, aplicados en el plano nacional, suelen dar resultados subóptimos en comparación con otras formas de regulación de la competencia, como las disposiciones antimonopolio, y pueden provocar distorsiones específicas, aunque se apliquen de acuerdo con las normas de la Organización Mundial del Comercio. Las restricciones nacionales sobre la movilidad de la mano de obra también crean distorsiones, en tanto que la asimetría de la movilidad de los factores (es decir, la mayor movilidad del capital y de la mano de obra calificada por oposición a la no calificada) dan origen a fuertes presiones negativas en la distribución del ingreso a nivel mundial. ${ }^{7}$

La segunda característica es la desorganización de los actores, sobre todo de los países en desarrollo, en el debate internacional, lo que no sólo es un reflejo del debilitamiento de los mecanismos de acción concertada (entre otros el Grupo de los 77), sino también de la "competencia de políticas" generada por la globalización, es decir el fuerte incentivo de los países a venderse como atractivos para la inversión en una época caracterizada por la movilidad del capital y por la pérdida de importancia de factores tradicionales de localización. Esto ha elevado el costo de crear coaliciones internacionales, e indica que la agenda internacional tenderá a mostrar sesgos aún más acentuados que en el pasado hacia aquélla de los países más grandes y las coaliciones mejor organizadas que, muy probablemente, no internalizarán en su totalidad los efectos que pueden tener sus políticas y agendas sobre el resto del mundo. A ello habría que agregar que, aunque la globalización también se caracteriza por el regionalismo abierto y que en muchas regiones en desarrollo se ha observado una fuerte tendencia a la integración (en América Latina y en el sudeste de Asia, entre otras), no han surgido coaliciones fuertes de países en desarrollo. En realidad, con la excepción de la Unión Europea, los países tampoco se muestran dispuestos a ceder su soberanía a instituciones regionales.

La desorganización de los actores está estrechamente relacionada con una tercera característica de la globalización: el carácter incompleto e incluso sesgado de la agenda internacional de políticas que acompaña a este proceso, es decir el fuerte impulso en determinadas direcciones, unido a la falta de considera-

\footnotetext{
${ }^{7}$ En relación con este último tema, véase Rodrik (1997).
}

ción de otros aspectos que también deberían formar parte de una globalización más equilibrada. Hay cuatro temas que se destacan en esta agenda: el libre comercio, los derechos de propiedad intelectual, la protección de las inversiones y la liberalización de la cuenta de capitales. Esta última ha sido matizada a raíz de las crisis de los últimos años, y hoy se considera que debe ser gradual, que debe centrarse en los flujos de capital a largo plazo, y que debe ir precedida del desarrollo de estrictas normas de regulación y supervisión prudencial. Por el contrario, hay temas que han sido ignorados en la agenda actual: la movilidad de la mano de obra, la aplicación de normas internacionales sobre tributación del capital (elemento esencial para garantizar la aplicación de impuestos adecuados a un factor de producción que se caracteriza por su notable movilidad), la formulación de normas sobre competencia y de códigos de conducta aplicables a las empresas multinacionales que sean auténticamente internacionales, el financiamiento y la transferencia de tecnología compensatorios con el fin de garantizar la incorporación de los países que suelen quedar rezagados en el proceso de globalización.

Todos estos elementos de economía política tienen implicaciones importantes sobre la reforma del sistema financiero internacional. Las más evidentes son que sólo existirá una débil presión para que se lleve a cabo una reforma sustancial, ${ }^{8}$ que es complejo diseñar un proceso equilibrado de negociación, y que en dicho proceso pueden subestimarse e incluso ignorarse los intereses de algunos actores. Obviamente, lo ideal sería que se optara por foros adecuados y una agenda amplia, que permitieran la debida representación de los intereses de aquellos actores que, de lo contrario, no recibirán mayor consideración. ${ }^{9}$ Estos elementos también implican que la arquitectura financiera internacional seguirá basándose fundamentalmente en una red de instituciones nacionales y, por lo tanto, que su principal función es ofrecer incentivos adecuados para que estas instituciones internalicen las externalidades que genera su interacción. A su vez, esto significa que la autonomía de los países seguirá desempeñando un papel fundamental en muchas áreas de política, si no en todas, y que instrumentos de política que han desaparecido a nivel nacional (entre otras, la imposición de

\footnotetext{
8 Véase Eichengreen (1998).

${ }^{9}$ Todas éstas son inquietudes fundamentales de Naciones Unidas, Grupo de Trabajo del Comité Ejecutivo de Asuntos Económicos y Sociales (1999a), del Grupo de los 24 (1998) y de Helleiner y Oyejide (1998).
} 
ciertos controles, o la suspensión unilateral del servicio de la deuda) probablemente deberán seguir considerándose como opciones válidas a nivel internacional.

Una implicación final y fundamental de la situación descrita es que ninguna arquitectura financiera internacional es neutral en términos del equilibrio de las relaciones internacionales. En el presente artículo se hace especial hincapié en que un sistema internacional basado exclusivamente en unas pocas instituciones internacionales es menos equilibrado que un sistema basado en una red de instituciones regionales, y que los países con muy escaso poder de negociación en el plano internacional se benefician con la existencia de una mayor variedad de alternativas para hacer frente a las posibles crisis o para financiar actividades de desarrollo y se perjudican si se ven limitados a unas pocas opciones. El primer aspecto de este postulado supone, de hecho, que el mejor mecanismo de defensa de los actores más débiles es la posibilidad de que exista competencia en la provisión de asistencia a ellos. El segundo apunta al hecho de que, en ausencia de apoyo internacional adecuado, la mejor alternativa puede ser una mayor, no una menor, autonomía nacional. Naturalmente, esta última tiene ciertos costos, dada la necesidad de contrapesar la mayor variedad de alternativas para hacer frente a las crisis con la necesidad de generar "credibilidad", factor que contribuye a que los países en desarrollo tiendan a adoptar aquellas políticas que, a su juicio, se considerarán "mejores prácticas" en el mercado, lo que es una consecuencia de la "competencia de políticas" a la cual hicimos alusión previamente.

\section{IV}

\section{Prevención y solución de crisis financieras}

Los temas relacionados con la prevención y solución de crisis financieras han sido objeto de gran atención en los debates recientes. ${ }^{10} \mathrm{El}$ tema en torno al cual existe un mayor acuerdo es la necesidad de mejorar el contexto institucional en el cual operan los mercados financieros, es decir de reforzar la regulación y supervisión prudencial y las prácticas contables de los sistemas financieros en todo el mundo; de adoptar estándares internacionales mínimos en estas áreas y principios adecuados sobre gobernabilidad empresarial, y de ofrecer mejor información a los mercados financieros. Desde el punto de vista de los países industrializados, las áreas más importantes de acción para los organismos nacionales pertinentes son la imposición de normas más estrictas de regulación y supervisión de las instituciones y transacciones con un alto grado de apalancamiento y de controles sobre los centros extraterritoriales, así como otorgar mayor peso a las regulaciones de los riesgos vinculados a operaciones con

\footnotetext{
10 Véanse, entre otros, Camdessus (1998a y1998b), FMI (1998), FMI, Comité Provisional de la Junta de Gobernadores sobre el Sistema Monetario Internacional (1998), Grupo de los Siete (1998), UNCTAD (1998), parte I, cap. IV), Naciones Unidas, Grupo de Trabajo del Comité Ejecutivo de Asuntos Económicos y Sociales (1999a), Miyazawa (1998), Rubin (1999), Akyüz y Cornford (1999), Eatwell y Taylor (1999), Eichengreen (1999), Griffith-Jones (1998), GriffithJones y Ocampo (1999), Ocampo (1999a y 1999b), White (1999) y Wyplosz (1999).
}

países con una deuda neta elevada, sobre todo de corto plazo, a fin de desalentar el financiamiento riesgoso en su fuente.

En las economías prestatarias, las autoridades regulatorias deberían otorgar más importancia a la acumulación de deudas de corto plazo en divisas, a los riesgos que supone la acelerada expansión del crédito, a los descalces de monedas entre activos y pasivos, y a la valoración de los activos fijos utilizados como garantía de los créditos en episodios de inflación del precio de los activos. Aun más importante, las autoridades deben tomar debidamente en consideración los vínculos que existen entre los riesgos financieros de los países y la variación de los instrumentos más importantes de política macroeconómica, en particular el tipo de cambio y las tasas de interés. Esto indica que las normas prudenciales deberían ser más estrictas en los países en desarrollo, en los que dichos vínculos son más fuertes, y que deberían reforzarse en períodos de euforia financiera, dados los riesgos crecientes a los que están expuestos los intermediarios financieros. También deben tomar en cuenta las importantes externalidades que pueden generar las empresas no financieras de gran tamaño sobre el sector financiero nacional, lo que establece también la conveniencia de regular la exposición al endeudamiento externo de dichas empresas. Este tema se analiza nuevamente en la sección VIII. 
Sin embargo, sigue habiendo discrepancias importantes con respecto a estos temas. Ante todo, no hay consenso sobre el tipo de instituciones a las que se debería asignar funciones más amplias en este campo. Es indudable que el Banco de Pagos Internacionales debería actuar como la entidad líder, pero esto exigiría que la institución contara con la participación de un número mucho mayor de países en desarrollo y que éstos ejercieran mayor influencia en la definición de todo tipo de estándares y códigos de conducta internacionales, en general. También convendría tener presente propuestas más ambiciosas formuladas en este ámbito, en especial la de crear una autoridad financiera mundial, con base en el Banco de Pagos Internacionales y en la Organización Internacional de Comisiones de Valores. ${ }^{11}$ En segundo término, aunque el objetivo esencial de la regulación y la supervisión prudencial es que los intermediarios financieros tomen más conciencia de los riesgos a los que se exponen, la conveniencia de desalentar a las entidades privadas a realizar actividades riesgosas tiene límites evidentes. En tercer lugar, hay ciertas discrepancias en cuanto a las ventajas relativas de la regulación y supervisión prudencial en comparación con el uso de otros instrumentos en áreas claves. Como se indica más adelante, uno de los temas más importantes que se plantean en este contexto es el relativo a la regulación de la cuenta de capitales. En cuarto lugar, hay profundas diferencias de opinión sobre qué se puede esperar de una regulación y supervisión prudencial más estrictas. Las regulaciones tienden a quedar rezagadas frente a las innovaciones financieras, los supervisores enfrentan serios problemas de información, e incluso los sistemas bien regulados pueden ser abrumados por ciertos fenómenos macroeconómicos. Por último, la regulación y supervisión prudencial de carácter tradicional suelen tener efectos macroeconómicos procíclicos (no impiden necesariamente la asunción de riesgos excesivos en períodos de auge y aceleran la restricción crediticia durante las crisis, cuando quedan en evidencia los préstamos incobrables y, por lo tanto, se manifiestan plenamente los efectos de las normas sobre constitución de reservas); este hecho puede acentuar, en lugar de mitigar, los riesgos crediticios a lo largo del ciclo económico.

No menos importantes son las dudas que se plantean en torno a qué se puede esperar de una mejor información. De hecho, aunque una mejor información

${ }^{11}$ Eatwell y Taylor (1999). realza la eficiencia microeconómica, es posible que no tenga efectos positivos sobre la estabilidad macroeconómica, que depende mucho más de la evolución de las opiniones y expectativas que de la información, en el sentido estricto del término (es decir, de información factual). La tendencia a considerar que las opiniones y expectativas son sinónimo de información es una de las confusiones más comunes que se encuentran en la literatura reciente sobre la materia. Los agentes bien informados (entre otros, las agencias calificadoras de riesgo y los inversionistas institucionales) también están sujetos a variaciones caprichosas de las opiniones y expectativas, hecho que explica su incapacidad para estabilizar los mercados y, en realidad, en determinadas circunstancias, el que puedan incluso acentuar la inestabilidad. ${ }^{12}$ Utilizando la terminología corriente, lo que caracteriza la inestabilidad financiera desde el punto de vista macroeconómico no son tanto las "cascadas de información" como las "cascadas de opiniones y expectativas", es decir la sucesión de episodios de contagio de optimismo y pesimismo a lo largo del ciclo económico. Ni siquiera el mejor sistema de información podría corregir esta "falla del mercado", dado que el capricho de las expectativas está asociado a "información" sobre el futuro, que nunca estará disponible. ${ }^{13}$

El consenso sobre la necesidad de reforzar el marco institucional en el que operan los mercados financieros no se ha visto complementado por un reconocimiento igualmente generalizado de la importancia de la coherencia de las políticas macroeconómicas a nivel mundial, es decir de mecanismos que permitan internalizar las externalidades creadas por las políticas macroeconómicas nacionales. Estos son fundamentales tanto en períodos de auge como de crisis, pero la necesidad de fortalecer las estructuras actuales extremadamente débiles adquiere particular relevancia en los primeros, cuando las autoridades nacionales perciben la supervisión del Fondo Monetario como un ejercicio académico, los mecanismos de consulta parecen menos necesarios y la "disciplina del mercado" tiene efectos perniciosos, porque no impide la asunción de riesgos excesivos ni la adopción de políticas nacionales procíclicas. En efecto, una de las deficiencias más

\footnotetext{
12 En relación con el primero de estos temas, véase Larraín, Reisen y Von Maltzan (1997); en relación con el segundo, Calvo (1998). ${ }^{13}$ En Ocampo (1999a) se presenta un análisis más detallado de este tema. El concepto del "concurso de belleza" desarrollado por Keynes es mucho más adecuado para analizar la volatilidad de las expectativas, como afirma categóricamente Eatwell (1996).
} 
graves de la estructura vigente es el hecho de que las actuales instituciones, nacionales e internacionales, otorgan mayor importancia a las crisis que a las fases de auge, lo que le resta peso al rol preventivo que deberían desempeñar. Obviamente, es fundamental que se tomen medidas expansionistas concertadas en períodos de crisis y tal como se afirma en la introducción de este artículo, es probable que las medidas de esa índole adoptadas a partir de la crisis rusa hayan sido la principal causa de la relativa pero incompleta normalización de los mercados de capital a lo largo de 1999. La falta de una representación adecuada de los países en desarrollo es otro de los defectos de la estructura actual. Las propuestas orientadas a fortalecer la supervisión de las políticas macroeconómicas del Fondo Monetario y de transformar su Comité Provisional en un Comité de Política Monetaria y Financiera son las más alentadoras, aunque esta última debería complementarse con la incorporación de un mayor número de países en desarrollo en dicho Comité. Además, dado el mayor equilibrio que presentan las Naciones Unidas en cuanto a la representación de países desarrollados y en desarrollo, esta institución también debería ejercer un rol más activo en la esfera normativa, ya sea por intermedio del Consejo Económico y Social o de un Consejo de Seguridad Económica.

La provisión de un mayor volumen de fondos de emergencia en períodos de crisis es el tercer pilar de un sistema capaz de prevenir crisis financieras y manejarlas en forma más adecuada una vez que se desencadenan. Este concepto podría definirse como el principio del "financiador de emergencia", para diferenciarlo del papel de "prestamistas de última instancia" que cumplen los bancos centrales a nivel nacional, papel que se diferencia en ciertos sentidos del desempeñado por el Fondo Monetario. Específicamente, lo que ofrece el Fondo es financiamiento excepcional, en ningún caso liquidez, lo que se refleja en la falta de disponibilidad automática de financiamiento cuando se produce una crisis. ${ }^{14}$ Los problemas de "riesgo moral" que genera este financiamiento plantea la necesidad de definir reglas de acceso para los prestatarios y de contar con mecanismos apropiados de renegociación de deudas, que garanticen una participación adecuada de los prestamistas privados en los costos de ajuste.

\footnotetext{
14 Esta importante distinción ha sido hecha por Helleiner (1999a). Véase Mohammed (1999), que presenta un análisis más detallado del tema y de su relación con el acceso del Fondo Monetario a recursos adecuados.
}

Las crisis de los últimos años nos dejan varias lecciones en este frente, entre las que destacan las siguientes: i) aunque puede ser necesario movilizar un gran volumen de fondos, no es necesario desembolsarlos en su totalidad, si los programas de apoyo permiten restablecer rápidamente la confianza del mercado; ii) que los fondos deben proporcionarse antes de que las reservas internacionales desciendan a un nivel crítico, no después de que esto ocurra; y iii) que debido a los importantes efectos de contagio, probablemente se requiere financiamiento para contingencias aun para países que no presentan desequilibrios fundamentales. De estas enseñanzas, por lo menos las dos últimas se apartan significativamente del enfoque tradicional del Fondo Monetario, basado en el principio de corrección de los desequilibrios fundamentales de la balanza de pagos cuando éstos se hacen evidentes. En este ámbito se han adoptado importantes decisiones, incluido el incremento de los recursos del Fondo mediante el aumento de las cuotas y la suscripción de los nuevos acuerdos para la obtención de préstamos, que entraron en vigor a fines de 1998; la apertura de un nuevo servicio en diciembre de 1997 para responder a las necesidades excepcionales de préstamos en casos de crisis, y la creación de líneas de crédito contingente en abril de 1999, con el fin de proporcionar financiamiento a países que han sufrido efectos de contagio, aunque en condiciones extremadamente restrictivas.

El financiamiento inadecuado, las condiciones de acceso y los términos crediticios son los temas que han despertado mayores controversias. En el primero de estos casos, el financiamiento bilateral y las contribuciones al Fondo Monetario seguirán siendo insuficientes en casos de crisis, lo que plantea un importante problema, dado que los programas de rescate no tendrán los efectos estabilizadores esperados si los mercados consideran que las autoridades involucradas (el Fondo Monetario y las fuentes de asistencia bilateral) no están en condiciones de proporcionar el volumen de fondos requerido o no están dispuestas a hacerlo. En vista de que el financiamiento bilateral y las contribuciones al FMI seguirán siendo insuficientes y poco confiables como mecanismo de financiamiento del Fondo en épocas de crisis, la solución óptima sería autorizar nuevas emisiones de derechos especiales de giro durante episodios de dificultades financieras a nivel mundial; dichos fondos podrían eliminarse una vez que se normalizara la situación. ${ }^{15}$ Este procedimiento intro-

\footnotetext{
15 Véase Naciones Unidas, Grupo de Trabajo del Comité Ejecutivo de Asuntos Económicos y Sociales (1999a).
} 
duciría un elemento anticíclico en el manejo de la liquidez mundial y daría a los derechos especiales de giro un papel más amplio en las finanzas mundiales, de conformidad con un principio propuesto por los países en desarrollo en el pasado y que deberían seguir propugnando. Las alternativas subóptimas son el recurrir con más frecuencia a operaciones swap entre los bancos centrales, bajo la dirección del Fondo Monetario o del Banco de Pagos Internacionales, y autorizar al FMI a recabar los fondos que requiera en el mercado.

En la sección VI se analizan los problemas que plantea la condicionalidad, pero en este contexto cabe destacar dos de ellos. En primer término, se ha sostenido que la concesión de líneas de crédito de contingencia para hacer frente a situaciones de contagio debería ser automática, siempre que los países cumplan con determinados requisitos previos, y que, por lo tanto, debería desvincularse de la condicionalidad tradicional. El servicio creado recientemente con tal propósito no cumple con todos estos criterios: aunque se otorgó mayor importancia a la celebración de las consultas previstas en el artículo IV del Convenio Constitutivo del Fondo, como mecanismos de determinación ex ante del acceso a financiamiento, para que éste se haga efectivo se siguen exigiendo negociaciones previas a la aprobación de la Junta de Gobernadores (un examen especial de "activación") y la suscripción de un acuerdo explícito de derecho de giro (standby agreement). Además, se estimó que los países con acceso actual a los recursos del Fondo Monetario no respondían a los criterios establecidos, lo que constituye una restricción importante, dado que margina a países que han mostrado una dinámica recuperación de crisis anteriores pero que siguen siendo deudores del Fondo. En segundo lugar, la combinación de la condicionalidad con la imposición de exigencias más estrictas en el caso de este servicio y de las operaciones de financiamiento excepcional (tasas de interés más altas y plazos más cortos de vencimiento) que las aplicadas tradicionalmente en las operaciones ordinarias del Fondo también ha provocado controversias. En realidad, esto elimina el carácter de "cooperativa de crédito" que tiene el Fondo, pero a la vez dista mucho de supuestas "condiciones de mercado".

La suspensión de pagos con anuencia internacional y las renegociaciones ordenadas de la deuda son mecanismos esenciales para evitar los problemas de coordinación implícitos en la fuga caótica de capitales, para garantizar una distribución adecuada de la carga del ajuste entre los prestamistas privados y, por lo tanto, para evitar los problemas de "riesgo moral" que pueden derivarse del financiamiento de emergencia. Debido a los efectos que podría tener el uso de este mecanismo en términos de acceso al mercado, es poco probable que los países prestatarios abusen de ellos. Sin embargo, para evitar problemas de "riesgo moral" por parte de estos últimos, tendrían que someterse a un control internacional, que podría consistir en exigir la aprobación previa del Fondo Monetario, o en autorizar a los países a decretar una suspensión unilateral de los pagos y luego someterla a la aprobación de un panel internacional independiente, que le daría legitimidad. ${ }^{16}$ Una tercera alternativa podría ser la formulación previa de reglas en virtud de las cuales el servicio de la deuda se suspendería o reduciría automáticamente en caso de producirse ciertas perturbaciones macroeconómicas; en algunos acuerdos de renegociación de deudas ya se han incluido reglas de esta naturaleza.

El uso de los mecanismos mencionados tiene cuatro efectos. El primero de ellos es que, para evitar el surgimiento de "beneficiarios gratuitos" (free riders) y la discriminación contra los países o grupos de países que los adopten, deben adoptarse en forma universal "cláusulas de acción colectiva" en las operaciones internacionales de concesión de préstamos. Los integrantes del Grupo de los Siete deberían encabezar este proceso, tal como lo propusieron en octubre de $1998,{ }^{17}$ porque de lo contrario podría convertirse en otra fuente de discriminación contra los "mercados emergentes". En segundo término, habría que estimular el financiamiento adicional de los acreedores (bailing in), dando prioridad a los préstamos que reciban los países que utilicen este mecanismo durante el período de vigencia de la suspensión de pagos y en una etapa posterior de "normalización" de los flujos de capital. En tercer lugar, las renegociaciones de deudas realizadas en este marco deberían atenerse a plazos cortos estrictamente definidos, que una vez vencidos facultaran al Fondo Monetario o al panel independiente a determinar las condiciones de la reprogramación. Por último, para evitar las renegociaciones reiteradas, que han sido la característica más problemática de las reprogramaciones de deudas en los últimos años, aparte de la porción que se condone o se renegocie en condiciones muy favorables, el servicio de la deuda restante debería depender de condiciones macroeconómicas contin-

\footnotetext{
16 UnCTAD (1998, parte I, cap. IV), y Naciones Unidas, Grupo de Trabajo del Comité Ejecutivo de Asuntos Económicos y Sociales (1999a).

${ }^{17}$ Grupo de los Siete (1998).
} 
gentes que determinan la capacidad de servicio de la deuda (términos del intercambio, normalización de la concesión de préstamos, actividad económica interna, etc).

Los procesos de reprogramación más difíciles de las últimas décadas han sido los que han involucrado a países pobres muy endeudados. La aplicación de la iniciativa destinada específicamente a estos países ha sido lenta, debido a la complejidad del proceso de selección de los países calificados (y, evidentemente, de definición de la condicionalidad pertinente) y a la falta de los recursos necesarios. ${ }^{18}$ La Iniciativa sobre la Deuda aprobada en Colonia (Alemania), podría ayudar a superar algunos de estos problemas, mediante la provisión de "alivio más rápido, más integral y más amplio". ${ }^{19}$ Obviamente, es esencial que, aparte de los criterios sobre calificación y el otorgamiento de las condiciones más generosas que sea posible, aumente la oferta de nuevos recursos. En particular, en un contexto caracterizado por la escasez de fondos de asistencia oficial para el desarrollo, es fundamental que los asignados al alivio de la deuda de los países pobres muy endeudados no desplacen la provisión de recursos frescos de asistencia oficial. Sería lamentable que se diera esa situación, dado que la provisión de nue- vos fondos es un complemento necesario del alivio de la deuda, y es poco probable que éste acelere, por sí solo, el crecimiento económico de los países pobres muy endeudados. Además, la falta de financiamiento adecuado ha dado origen a una demanda adicional que se cubre con ingresos netos (utilidades) de los bancos de desarrollo, motivo por el cual algunos de ellos, incluido el Banco Mundial, han ampliado los márgenes $\mathrm{y}$, por lo tanto, elevado las tasas de interés aplicables a sus préstamos. Paradójicamente, esto significa que otros países en desarrollo deudores acabarán cubriendo parte del alivio de la deuda. Los problemas de financiamiento adquieren particular gravedad en el caso de los bancos regionales y subregionales de desarrollo, lo que puede llegar a dificultar notablemente algunas de sus actividades en caso de que los fondos fiduciarios diseñados en el marco de la iniciativa no cubran adecuadamente el costo del alivio de la deuda.

La definición de normas internacionales sobre regulación de la cuenta de capitales y regímenes cambiarios no se incluye en esta sección, debido a que, dado el carácter incompleto de las estructuras financieras mundiales actuales, la autonomía nacional debería continuar rigiendo en estas áreas, según se analiza en la sección VIII de este ensayo.

\section{Financiamiento para el desarrollo}

Como se señala en la sección II, aunque el financiamiento adecuado del Fondo Monetario es indudablemente importante para los países de bajos ingresos, el problema más grave al que se enfrentan es la necesidad de asegurar un financiamiento apropiado para el desarrollo, a través de la asistencia oficial con ese fin o de préstamos multilaterales, y de la creación de mecanismos que les permitan participar más activamente en los mercados privados de capital. Dada la magnitud relativa del financiamiento destinado a países de bajos ingresos (véase el cuadro 2), la reversión de la tendencia a la disminución de los flujos de asistencia oficial para el desarrollo, sobre todo de los provenientes de las economías industrializadas de mayor tama-

\footnotetext{
18 Naciones Unidas, Grupo de Trabajo del Comité Ejecutivo de Asuntos Económicos y Sociales (1999b).

${ }^{19}$ Grupo de los Siete (1999).
}

ño, es el elemento más importante. Como ya se ha dicho, es necesario que los esfuerzos destinados a acelerar la aplicación de la iniciativa para los países pobres muy endeudados no se traduzcan en una disminución en el suministro de recursos frescos de asistencia oficial para el desarrollo en el presupuesto de los países industrializados. De hecho, más allá de una iniciativa más ambiciosa para los países pobres muy endeudados, el mundo necesita una "Iniciativa de asistencia oficial para el desarrollo" más ambiciosa y estable, que permita alcanzar las metas que se establezcan a nivel internacional. Como se afirma en las siguientes secciones, una de las características esenciales de este proceso debería ser la "propiedad" efectiva de las políticas por parte de los países en desarrollo, proceso que supone una menor orientación externa y una mayor valoración de las instituciones nacionales de desarrollo. Esto último exige, a su vez, que se respete el papel fundamental que deberían desempeñar los 
parlamentos y los gobiernos de los países receptores de asistencia en la asignación global de asistencia a través de su proceso presupuestal, y la función esencial de los gobiernos de esos países en las áreas tradicionales de las políticas públicas, como la infraestructura y la política social, incluso en aquellos casos en que se otorga a la sociedad civil un papel central en la aplicación de tales políticas.

Sin embargo, tan importante como lo anterior es la aceleración del crecimiento del financiamiento multilateral. Además, debido a la notable concentración de los flujos privados en unas pocas economías emergentes, los préstamos multilaterales seguirán desempeñando un papel fundamental, incluso en el caso de los países de ingreso medio. En términos más generales, el financiamiento multilateral seguirá siendo esencial por lo menos en las siguientes áreas: i) la canalización de fondos a los países de bajos ingresos; ii) la provisión de financiamiento a largo plazo a los países de ingreso medio y a los países pequeños que, por no estar bien calificados como prestatarios o por los costos fijos de ciertas operaciones (en el caso del financiamiento mediante la emisión de bonos, entre otros), no tienen un acceso adecuado a recursos privados; iii) la compensación anticíclica de las fluctuaciones del financiamiento proveniente del mercado privado de capitales; y iv) la facilitación de la transición a nuevas formas de financiamiento privado. A estas áreas habría que sumar el "valor agregado" tradicional del financiamiento multilateral, es decir la asistencia técnica vinculada al otorgamiento de préstamos.

La primera de estas funciones pone de manifiesto el papel fundamental que seguirá ejerciendo el financiamiento del Banco Mundial, de la Asociación Internacional de Fomento y de los bancos regionales y subregionales de desarrollo en el futuro inmediato. La segunda y tercera funciones destacan el papel que seguirá desempeñando la asistencia oficial para el desarrollo, incluso para los países de ingreso medio. Sin embargo, cabe destacar que la provisión anticíclica de fondos no debe confundirse con la provisión de financiamiento de emergencia para la balanza de pagos, que es esencialmente una función del Fondo Monetario Internacional. De todos modos, la necesidad de un cuantioso financiamiento anticíclico para los países de medianos ingresos en períodos de crisis puede llegar a reducir la concesión de fondos a países pobres, hecho que ha sido destacado por el presidente del Banco Mundial. ${ }^{20}$ Por lo tanto, en la medida en que

20 Wolfensohn (1998). el financiamiento multilateral para el desarrollo no se incremente significativamente, su papel anticíclico seguirá siendo muy limitado y, sin duda, tendrá una importancia secundaria en relación con las dos primeras funciones, sobre todo el otorgamiento de préstamos a largo plazo para el desarrollo de los países pobres. Esto queda en evidencia en el cuadro 2, en el que se observa que en el período 1992-1997 el financiamiento multilateral representó apenas el 13\% del proporcionado por el sector privado, con la excepción de la inversión extranjera directa, y sólo un $6 \%$ en el caso de los países de ingreso medio. Por consiguiente, el desempeño de una eficiente función anticíclica exige un incremento notable de los recursos.

La cuarta función tiene un origen relativamente reciente, pero ha ido adquiriendo mayor importancia en los años noventa y debería convertirse en uno de los componentes más destacados del financiamiento multilateral en el futuro. En los últimos años esta función ha estado relacionada con el financiamiento directo al sector privado (ya sea de los bancos o de las corporaciones financieras vinculadas a éstos) o con el diseño de regímenes destinados a garantizar la prestación de apoyo a proyectos privados de infraestructura en países en desarrollo. Otro de sus objetivos podría ser el facilitar la reincorporación a los mercados de los países en desarrollo en períodos de crisis y, lo que es aún más importante, apoyar las emisiones iniciales de bonos de estos países, sobre todo los pobres, interesados en integrarse a los mercados privados de capitales. Esto podría lograrse mediante el establecimiento de regímenes de cofinanciación o de provisión de garantías. Debe resaltarse que el cabal desarrollo de este último mecanismo exigiría una drástica modificación del manejo de las garantías por parte de los bancos de desarrollo; de acuerdo con la metodología vigente, éstas se consideran equivalentes a la concesión de préstamos, práctica que limita notablemente la capacidad de los bancos para otorgarlas. Esta ampliación del papel de los bancos de desarrollo en lo que respecta a la provisión de garantías al financiamiento privado ha sido criticada, por considerarse que podría exponer a estas instituciones a riesgos excesivos. Pese a esto, en un mundo que estará dominado por el financiamiento privado, tal vez sea imprescindible para evitar que los países de bajos ingresos queden al margen de los importantes desarrollos que vienen experimentando los mercados de capitales, por lo que este tema debería recibir atención prioritaria en las discusiones en curso.

En los debates recientes sobre estos temas también se ha tenido debidamente en cuenta la importan- 
cia de la función que deberían desempeñar los bancos multilaterales de desarrollo en el financiamiento de redes de protección social en los países en desarrollo. De hecho, la existencia de redes sólidas de protección social es esencial para hacer frente a las repercusiones sociales de la vulnerabilidad financiera del mundo en desarrollo. Existe, sin embargo, cierta confusión con respecto al concepto, que se aplica tanto para referirse a la formulación de políticas sociales de largo alcance como a mecanismos específicos destinados a proteger a los sectores vulnerables en períodos de crisis. Probablemente el término sólo debería aplicarse en el segundo caso, aunque, como se comenta más adelante, estas redes deberían formar parte de mecanismos estables de protección social. A pesar de que los bancos multilaterales tienen una larga historia de participación en el primero de estos ámbitos y también han acumulado cierta experiencia en el segundo, el mecanismo preferido desde fines de los años ochenta han sido los fondos sociales de emergencia, que en muchos países se transformaron posteriormente en fondos más estables de inversión social. Aunque han introducido algunas innovaciones en la política social, como el establecimiento de mecanismos competitivos para la asignación de recursos y la participación de la sociedad civil en las políticas sociales, sus efectos han sido más bien limitados, su focalización no ha sido siempre eficaz y es posible que hayan absorbido recursos que podrían haberse destinado a políticas sociales de largo alcance. ${ }^{21}$ Los países en desarrollo también han recurrido a otros instrumentos en el pasado, incluidos diversos seguros de desempleo (el principal instrumento de esta naturaleza empleado en los países industrializados), programas de empleo de emergencia o programas de emergencia de obras públicas intensivas en mano de obra, sistemas de apoyo a los ingresos vinculados a capacitación y algunos programas de nutrición. Al parecer, la crisis reciente ha conducido al diseño de nuevos instrumentos: la provisión de sub-

${ }^{21}$ Véase, en particular, Cornia (1999). Véanse también CEPAL (1998b, cap. VI), Graham (1994) y Lustig (1997). sidios especiales a los hogares con niños en edad escolar, con la condición de que éstos sigan asistiendo a clases, y diversos programas de apoyo destinados a evitar que las unidades familiares encabezadas por una persona desempleada pierdan su vivienda durante la crisis.

Análisis recientes de estos programas permiten llegar a algunas conclusiones básicas. En primer término, las redes deben ser un elemento permanente de los regímenes de protección social, dado que sólo un régimen estable puede asegurar que la cobertura de los programas responde de inmediato a la demanda de protección de los sectores vulnerables en épocas de crisis. ${ }^{22} \mathrm{~A}$ su vez, esto significa que el financiamiento debe provenir en su mayor parte del propio país e incluir una proporción muy limitada de fondos externos, cuya contribución en épocas de crisis podría ser marginal e incluso nula, tal como se indica más adelante. En segundo lugar, la heterogeneidad de los mercados de trabajo en los países en desarrollo hace necesaria una combinación de programas con distintos grupos destinatarios. ${ }^{23}$ En tercer término, estos programas deben contar con financiamiento adecuado y no deben absorber recursos destinados a inversiones a largo plazo en capital humano. Esto apunta, a su vez, a una cuarta conclusión, según la cual el funcionamiento efectivo de redes de protección social exige que algunos componentes del gasto público deben tener un comportamiento anticíclico. Esto sólo es posible, sin generar ineficacias en los demás componentes del gasto público, si la política fiscal como un todo no es anticíclica. Este es tema al cual no se ha otorgado la importancia debida en los debates recientes sobre la materia. Por lo demás, si la política fiscal no es anticíclica, el financiamiento externo de los bancos de desarrollo para las redes durante las crisis sería innecesario o, en el mejor de los casos, ilusorio, dada la disminución del financiamiento fiscal neto requerido, pese al aumento de los gastos asociado a las redes de protección social.

\footnotetext{
${ }^{22}$ Esta conclusión se destaca en el mejor análisis del tema (Cornia, 1999), en el que también se insiste en la necesidad de un financiamiento adecuado.

${ }^{23}$ Márquez (1999).
} 


\section{VI}

\section{Condicionalidad vs. "propiedad" de las políticas económicas}

La condicionalidad es, sin duda, el aspecto más polémico del financiamiento internacional de emergencia o para el desarrollo. En el caso del Fondo Monetario, ha sido por mucho tiempo un tema polémico, pero en los últimos años, e incluso décadas, ha ido despertando una creciente inquietud, por tres razones diferentes. En primer término, el alcance de la condicionalidad se ha ido expandiendo gradualmente, de tal modo que hoy en día se extiende no sólo a los ámbitos propios de otras organizaciones internacionales - con frecuencia, por ejemplo, al de la Organización Mundial del Comercio y de los bancos de desarrollo-, sino también a las estrategias nacionales de desarrollo económico y social y a instituciones que, como ha indicado el Grupo de Trabajo del Comité Ejecutivo de Asuntos Económicos y Sociales de las Naciones Unidas, "por su misma naturaleza, deben ser determinadas por las autoridades nacionales legítimas, sobre la base de un amplio consenso social". ${ }^{24}$ En segundo lugar, si bien la legitimidad de la condicionalidad es innegable en aquellos casos en que las políticas adoptadas por un país son la fuente de los desequilibrios macroeconómicos que generan los problemas financieros y es necesaria para evitar el "riesgo moral", no es claro cómo debe aplicarse este principio cuando los problemas han sido provocados por una crisis internacional y, sobre todo, por efectos de contagio. Como ya se ha señalado, es aún menos claro por qué la condicionalidad debería combinarse en estos casos con condiciones crediticias adversas. Por último, muchos observadores han criticado el sobreajuste que caracteriza algunos programas del Fondo Monetario, razón por la cual este organismo ha optado por dejar abiertos ciertos márgenes para la adopción de políticas fiscales anticíclicas en sus programas de ajuste, como se señaló anteriormente.

Incluso si la legitimidad del principio de condicionalidad - $\mathrm{o}$, como se define en algunos casos, de "apoyo a cambio de reformas" - resulta aceptable, hay razones que justifican un análisis de sus característi-

\footnotetext{
${ }^{24}$ Naciones Unidas, Grupo de Trabajo, del Comité Ejecutivo de Asuntos Económicos y Sociales (1999a, sección 5). Véase también Grupo de los 24 (1999), Feldstein (1998) y Rodrik (1999b).
}

cas. De hecho, la percepción de que la condicionalidad ha llegado a superar el ámbito de lo necesario para que el Fondo cumpla adecuadamente sus funciones puede contribuir a reducir su legitimidad. Por eso, se podría afirmar categóricamente que, si se desea que el principio de condicionalidad vuelva a despertar absoluta confianza, debería alcanzarse un nuevo acuerdo internacional sobre sus modalidades de uso.

Hay varios principios que podrían formularse al respecto. Ante todo, la condicionalidad del FMI debería limitarse a las políticas macroeconómicas en las que se centraba en el pasado e imponerse en aquellos casos en que exista un evidente vínculo entre políticas expansionistas y surgimiento de desequilibrios macroeconómicos. También podría ser necesario exigir reformas de la regulación y supervisión prudencial nacional, pero en tal caso deberían suscribirse acuerdos paralelos con las autoridades internacionales pertinentes (tema sobre el cual existen opiniones diferentes, según hemos visto). En segundo lugar, cuando la fuente del desequilibrio es una perturbación externa se debería dar acceso a un volumen apropiado de fondos de baja condicionalidad. Este principio debería reconocerse plenamente en la nueva línea de crédito contingente para países que son víctimas de efectos de contagio. No obstante, más allá del límite preestablecido para estos servicios, el acceso a recursos del Fondo podría estar sujeto también a condicionalidad macroeconómica en términos tradicionales. En tercer término, como ya se ha comentado, no se deberían imponer condiciones crediticias más estrictas como complemento de la condicionalidad. En cuarto lugar, cuando un país suscriba un acuerdo con el Fondo Monetario se deberían adoptar, de común acuerdo, reglas automáticas en virtud de las cuales las restricciones impuestas en el programa de ajuste se reducirían si se hiciera evidente que son excesivas. Por último, se deberían realizar evaluaciones periódicas oficiales de los programas del Fondo, ya sea a cargo de una división autónoma de la misma institución, como ocurre en el Banco Mundial, o de analistas externos; una vez que la Junta de Gobernadores examinara las principales conclusiones de estos ejercicios, deberían incorporarse a las prácticas ordinarias del Fondo. 
El financiamiento para el desarrollo plantea interrogantes similares a los descritos. En relación con este tema, en un informe del Banco Mundial de reciente publicación, en el que se analizan los resultados de los préstamos estructurales, de acuerdo a la evaluación del propio Banco, se concluye que la condicionalidad no influye en el éxito o fracaso de dichos programas. ${ }^{25}$ No obstante, en el mismo informe se afirma que la eficacia de la ayuda no es independiente de las políticas económicas que aplican los países. En particular, la ayuda contribuye en mayor medida al crecimiento en los países que adoptan políticas "adecuadas" lo que, según su propia definición (obviamente discutible en casos particulares), comprende la creación de condiciones macroeconómicas estables, la adopción de regímenes de libre comercio, la protección adecuada de los derechos de propiedad y la existencia de una burocracia pública eficiente capaz de prestar buenos servicios sociales. En lo que atañe a las políticas adecuadas, la ayuda tiene otro efecto positivo: la "atracción" de financiamiento privado. En cambio, en los países que adoptan políticas "inadecuadas" no se observa ninguno de estos efectos. Utilizando la terminología que se ha popularizado en la literatura sobre ayuda para el desarrollo, lo más importante es la "propiedad" (ownership) de políticas económicas adecuadas por parte de los países, es decir, el compromiso de las autoridades nacionales con dichas políticas. La condicionalidad no aporta nada en estos casos y es evidentemente ineficaz en países que no aplican políticas adecuadas.

Curiosamente, en su estudio el Banco Mundial llega a la conclusión de que, después de todo, la condicionalidad es positiva. "Los préstamos sujetos a condicionalidad", se afirma en el estudio, "se justifican cuando las reformas cuentan con un gran respaldo nacional" 26 y, sobre todo, "puede cumplir el papel de permitir al gobierno que exprese su adhesión a la re- forma y dé señales de la seriedad de ésta, pero para hacerlo en forma eficaz tiene que centrarse en un número limitado de medidas realmente importantes". ${ }^{27} \mathrm{Si}$ las conclusiones del estudio se interpretan en forma estricta, esta afirmación no deja de ser paradójica. Más bien, el estudio aludido plantea serias dudas sobre la racionalidad de la condicionalidad, lo que por lo demás está implícito en la idea de que lo fundamental es la "propiedad" de las políticas económicas. ${ }^{28}$

En un análisis reciente, Rodrik llega a conclusiones complementarias, en relación con las políticas macroeconómicas de corto plazo. ${ }^{29}$ Además de sostener que los regímenes internacionales deben permitir la adopción de diversas estrategias nacionales de desarrollo (diferentes "tipos de capitalismo"), este autor afirma categóricamente que la existencia de instituciones adecuadas de resolución de conflictos, instituciones que sólo pueden existir en el contexto de procesos democráticos nacionales, es un elemento esencial de la estabilidad macroeconómica y, a su vez, del crecimiento económico. Recurriendo al término ya empleado en otro contexto, la "propiedad" de los programas de ajuste macroeconómico también es esencial para garantizar su sostenibilidad política.

En realidad, la contraposición de la condicionalidad con la propiedad de las políticas económicas de un país es fundamental para los objetivos más amplios de fomento de la democracia a nivel mundial. Es evidente que no tiene ningún sentido fomentar la democracia si no se permite que los procesos representativos y participativos que se llevan a cabo en un país contribuyan a la determinación de las estrategias de desarrollo económico y social, y a la combinación específica de políticas que conduce a la estabilidad macroeconómica. Es posible que éstas no sólo sean relativamente ineficaces, sino que además carezcan de sostenibilidad política si las instituciones internacionales o los organismos de asistencia de los países industrializados desempeñan esta función.
25 Véase Banco Mundial (1998b, cap. 2 y anexo 2).
26 Ibid, p. 48.

\footnotetext{
27 Ibid, p. 49.

${ }^{28}$ Véase un análisis detallado de estos temas en Helleiner (1999b).

${ }^{29}$ Rodrik (1999a).
} 


\section{VII}

\section{El papel de las instituciones regionales}

Hay por lo menos tres razones que justifican el que las instituciones regionales desempeñen un papel importante en el nuevo orden financiero internacional. La primera de ellas es que, como ya se ha señalado, la globalización es también un mundo de regionalismo abierto. La expansión del comercio y de los flujos de inversión directa intrarregionales son características destacadas del proceso actual de globalización. Ello refuerza los vínculos macroeconómicos $\mathrm{y}$, por lo tanto, las demandas de prestación de ciertos servicios por parte del sistema financiero internacional que han sido analizados en las secciones anteriores: supervisión macroeconómica e internalización de las externalidades que suponen las políticas macroeconómicas de un determinado país para los países vecinos, supervisión mutua de los mecanismos de regulación y supervisión prudencial del sistema financiero y los efectos regionales de los posibles procesos de suspensión de pagos y de renegociación de deudas.

En segundo lugar, algunos de estos servicios pueden estar sujetos a deseconomías de escala y no se sabe con certeza si, por el contrario, otros se caracterizan por economías de escala tan considerables que justifican la existencia de una sola institución internacional en las áreas correspondientes (es decir, tienen la característica de monopolios naturales). Esto plantea problemas clásicos de subsidiariedad. Por ejemplo, es posible que para garantizar la coherencia de las políticas de los principales países industrializados haya que recurrir a consultas y supervisión macroeconómicas a nivel mundial, pero indudablemente éstas no harían ningún aporte al manejo de las externalidades de las políticas de esa índole entre países vecinos en el mundo en desarrollo, o aun dentro de Europa. Dadas las diferencias existentes entre distintas tradiciones jurídicas y las deseconomías correspondientes, la supervisión de los sistemas nacionales de regulación y supervisión prudencial del sector financiero, e incluso la formulación de "estándares mínimos" específicos en esta área, podrían llevarse a cabo mucho más adecuadamente con el apoyo de instituciones regionales. El financiamiento para el desarrollo puede operar eficazmente en distintas escalas y, como se indica más adelante, en el plano regional y subregional puede cumplir ciertas funciones que no podrían desempeñarse a nivel internacional. Por otra parte, aunque la posibilidad de contagio regional e internacional implica que el manejo de las crisis de balanza de pagos de mayor tamaño debería asignarse a una sola institución mundial, es difícil saber cuán lejos es posible llevar esta afirmación. Las instituciones regionales sólidas pueden actuar como verdaderos amortiguadores en ese plano, como lo enseña la experiencia de Europa occidental en el período de posguerra. Además, los fondos regionales de reserva pueden hacer un aporte incluso en los casos de crisis más graves (como lo demuestra el Fondo Latinoamericano de Reserva, anteriormente Fondo Andino de Reserva) y, en caso de ampliarse, pueden incluso dar pleno apoyo a los países pequeños y medianos en algunas regiones. Como queda en evidencia en la creciente concentración de apoyo para balanza de pagos en unos pocos países (véase la sección II), también es posible que exista un sesgo en la respuesta de la comunidad internacional en función del tamaño de los países, hecho que justificaría la división de funciones en la prestación de servicios en esta área entre las organizaciones mundiales y regionales.

El tercer argumento ya ha sido expuesto en la sección III: en el caso de los países pequeños, el acceso a una mayor variedad de alternativas para hacer frente a una crisis o para financiar actividades de desarrollo es relativamente más importante que los "bienes públicos globales" que proporcionan las organizaciones internacionales más grandes (la estabilidad macroeconómica global, entre otros), en cuya provisión ejercen una mínima influencia o no influyen en absoluto (lo que equivale a adoptar una actitud de "beneficiario gratuito"). Debido a su tamaño reducido, su poder de negociación ante las grandes organizaciones es muy limitado, por lo que su mecanismo de defensa más importante es la competencia en la prestación de servicios financieros que se les suministran.

Es posible que haya un cuarto argumento, de economía política: los países tienen la tendencia a reaccionar de muy distintas maneras ante los análisis que realizan las organizaciones internacionales y regionales, y a la condicionalidad que implican. De acuerdo con la terminología empleada en la sección anterior, es probable que sientan como más "propios" los análisis de estas últimas, por considerar que pueden influir 
más en ellos, hecho que lejos de reducir su eficacia, la realza. El temor de que esto pueda conducir a la adopción de regímenes demasiado laxos es injustificado, ya que las propuestas de creación y fortalecimiento de instituciones financieras regionales llevan aparejados compromisos financieros de los países en desarrollo, en la forma de aportes al capital necesario a los correspondientes fondos de reserva y bancos de desarrollo, lo que se traduce en un control estricto de la solidez de sus actividades por parte de los países. En realidad, la disponibilidad de capital es el elemento restrictivo más importante del crecimiento de estas redes financieras regionales. La posibilidad de que muchas de ellas capten fondos en el mercado constituye otro medio de fiscalización de sus operaciones.

Las discusiones actuales han puesto de relieve la insuficiencia de algunos de los servicios que prestan las instituciones financieras internacionales, incluida la provisión de ciertos "bienes públicos globales". Sin embargo, esta afirmación no debería llevar a concluir que la ampliación de la oferta de dichos servicios debería provenir de unas pocas organizaciones mundiales. Más bien, la estructura organizativa deseable debería consistir, en algunos casos, en una red de instituciones que presten los servicios requeridos en forma complementaria y, en otros, en un sistema de organizaciones competitivas. La prestación de los servicios necesarios para la prevención y el manejo de crisis financieras debería regirse por el primer modelo, en tanto que la competencia debería ser el principio rector en el ámbito del financiamiento del desarrollo, incluyendo la competencia con agentes privados. Pero es probable que la pureza del modelo no sea la característica ideal, ya que puede ser conveniente que algunos componentes de las redes compitan entre sí (por ejemplo, que los fondos regionales de reserva compitan con el Fondo Monetario Internacional en la provisión de financiamiento de emergencia) y que las organizaciones competitivas cooperen en algunos casos.

Esto implica que el Fondo Monetario Internacional del futuro no debería visualizarse como una institución global única, sino como el vértice de una red de fondos regionales y subregionales de reserva. Para fomentar la creación de estos últimos se podrían establecer incentivos que dieran a los fondos comunes de reserva acceso automático a financiamiento del Fondo o cierta participación en la asignación de derechos especiales de giro proporcional a su capital pagado, o ambas cosas, lo que equivaldría a considerar las contribuciones a estos fondos como un equivalente del pago de cuotas al Fondo. ${ }^{30}$ Como ya se ha señalado, los fondos regionales de reserva podrían proporcionar la mayor parte del financiamiento excepcional a los países pequeños de la región correspondiente, pero podrían también aportar parte del financiamiento destinado a países más grandes, y contribuirían a disuadir, al menos en parte, a posibles especuladores de realizar operaciones contra la moneda de un país.

Este modelo debería hacerse extensivo a las consultas y supervisión en el ámbito macroeconómico, como también a la coordinación y fiscalización de los sistemas nacionales de regulación y supervisión prudencial. Por consiguiente, habría que concebir sistemas regionales y subregionales, incluidos mecanismos de evaluación de pares, con el fin de internalizar las externalidades generadas por las políticas macroeconómicas de un país sobre sus países vecinos. Estos no sustituirían la supervisión regular del Fondo Monetario, sino que la complementarían. En el área de la regulación y la supervisión prudencial, la creación de sistemas regionales de información y consulta más complejos, incluida la adopción de "estándares mínimos" de alcance regional, también podrían cumplir un papel positivo. En estos sistemas también se debería contemplar la evaluación de pares. En los casos de suspensión de pagos y de renegociación de deudas, los mecanismos regionales deberían, como mínimo, cumplir un rol de evaluación de los efectos concretos que dichos procesos podrían tener en la región.

Es importante recalcar que, además de las funciones consideradas en la sección $\mathrm{V}$, los bancos subregionales de desarrollo pueden cumplir un importante papel como mecanismo para que un conjunto de países en desarrollo comparta los riesgos, lo que les permitiría un aprovechamiento más dinámico de las oportunidades que ofrecen los mercados privados de capital. En América Latina, un ejemplo interesante en este sentido es la Corporación Andina de Fomento, cuya propiedad está enteramente en manos de países en desarrollo. El hecho de que la calificación de riesgo de esta institución haya sido superior a la de Colombia (el único país de la región andina que en los años noventa ha sido calificado con "grado de inversión"), lo que le ha permitido colocar instrumentos de deuda en condiciones favorables, indica que la estrategia de "compartir los riesgos" puede ser eficaz.

\footnotetext{
${ }^{30}$ Naciones Unidas, Grupo de Trabajo del Comité Ejecutivo de Asuntos Económios y Sociales (1999a, sección 9) y Ocampo (1999a)
} 
Como se sabe ampliamente, Europa occidental proporciona el mejor ejemplo de cooperación financiera regional en la posguerra. Los Estados Unidos, a través del Plan Marshall, sirvieron como catalizador en las fases iniciales de este proceso, que experimentó una profundización muy dinámica desde el diseño de la Unión de Pagos Europea hasta una serie de arreglos de coordinación y cooperación macroeconómica, que eventualmente condujeron a la actual unión monetaria de la mayoría de sus miembros. La historia de muchas instituciones, incluido el Banco de Pagos Internacionales, está asociada a estos esfuerzos de cooperación. En etapas diferentes, estas instituciones demostraron que los esquemas regionales podían hacer una contribución fundamental a la estabilidad de la economía mundial. No se han diseñado esquemas similares en el resto del mundo, aunque se han hecho muchas sugerencias, la más ambiciosa de las cuales fue la propuesta japonesa de crear un fondo monetario asiático.

En escala mucho más limitada, existen instituciones que han desempeñado un papel importante en el mundo en desarrollo, en especial en el área de financiamiento del desarrollo. En América Latina y el Caribe, por ejemplo, el Banco Interamericano de Desarrollo (BID) supera al Banco Mundial en términos de financiamiento para el desarrollo en la región. La
Corporación Andina de Fomento supera, a su vez, al BID en el financiamiento hacia la región andina en años recientes. El Fondo Andino, ahora Latinoamericano de Reservas, ha jugado un papel limitado pero constructivo en el apoyo a la balanza de pagos de los países andinos durante las dos últimas décadas. Bajo los arreglos de integración existentes, se han iniciado diálogos orientados a la coordinación macroeconómica, pero los avances han sido limitados en esta área. En cualquier caso, el llamado a desarrollar esquemas de coordinación macroeconómica más fuertes ha sido un tema común durante la crisis reciente.

Un marco institucional como el propuesto tendría dos características positivas. En primer lugar, podría contribuir a dar mayor estabilidad a la economía mundial, mediante la prestación de servicios esenciales que difícilmente pueden proporcionar unas pocas instituciones internacionales, sobre todo en el contexto de un proceso dinámico de regionalismo abierto. En segundo término, desde el punto de vista del equilibrio de las relaciones mundiales, sería preferible a un sistema basado en unas pocas organizaciones mundiales, lo que reforzaría el compromiso de respetar las reglas que contribuyen a la estabilidad mundial y regional por parte de los participantes con menor poder.

\section{VIII}

\section{Las esferas de la autonomía nacional}

Independientemente de las características que tenga un nuevo sistema internacional, es indudable que seguirá siendo una "red de seguridad financiera" muy imperfecta, por lo que la adopción de un cierto grado de "autoseguro" por parte de los países seguirá siendo fundamental para impedir las crisis financieras y, asimismo, para evitar los problemas de "riesgo moral" que son un elemento intrínseco de todo programa de apoyo. Esto plantea interrogantes tanto en torno a las políticas nacionales necesarias para asegurar la estabilidad financiera como a las áreas en que debería preservarse la autonomía nacional. A nuestro juicio, por lo menos en el caso de los países en desarrollo, el sistema internacional debería seguir reconociendo la autonomía nacional en dos áreas fundamentales: el manejo de la cuenta de capitales y la elección del régimen cambiario. Sin lugar a dudas, la elección de la estrategia de desarrollo es otra esfera esencial en que la au- tonomía nacional debería seguir imperando, como se señaló enfáticamente en la sección VI.

La experiencia de los países en desarrollo indica que el manejo de la volatilidad de la cuenta de capitales exige: i) una gestión macroeconómica consistente y flexible; ii) normas estrictas de regulación y supervisión prudencial de los sistemas financieros nacionales; y iii) "políticas de pasivos" estrictas, destinadas a inducir un perfil adecuado de la deuda pública y privada, tanto interna como externa. ${ }^{31}$ Aunque el énfasis tradicional ha recaído en el manejo de las crisis, las autoridades deberían centrar su atención en el manejo de las bonanzas, ya que las crisis se incuban precisa-

\footnotetext{
31 Actualmente existe una extensa literatura sobre el tema de las políticas nacionales. Entre otras, véanse las recientes contruibuciones de CEPAL (1998a y 1998c), Banco Mundial (1998a, cap. 3), FfrenchDavis (1999), Helleiner (1997) y Ocampo (1999b).
} 
mente durante los períodos de euforia de afluencia de capital, expansión del comercio y mejoramiento de los términos del intercambio. Por lo tanto, la prevención de crisis está estrechamente vinculada al manejo adecuado de los períodos de auge.

La naturaleza de las políticas que se adopten variará, como es obvio, de acuerdo a las características estructurales de las distintas economías, como también de su tradición macroeconómica y su nivel de desarrollo. En el área macroeconómica, los dos principales objetivos deben ser el evitar que los agentes públicos o privados acumulen deudas en magnitudes insostenibles durante las épocas de auge y evitar, asimismo, los desequilibrios de los precios más importantes, sobre todo del tipo de cambio y de los precios de los activos nacionales. En la esfera fiscal, la atención debe centrarse en la sostenibilidad de los coeficientes de endeudamiento público a lo largo del ciclo económico, lo que exige un fortalecimiento fiscal en las épocas de bonanza, que otorgue a las autoridades los grados de libertad necesarios para mitigar en cierta medida las restricciones fiscales en la fase descendente posterior, e impedir, así, que se produzca una contracción excesiva de la actividad económica. En cambio, como se sabe ampliamente, en economías abiertas las autoridades tienen limitaciones considerables para adoptar políticas monetarias y de crédito interno restrictivas en períodos de auge, si las entradas de capitales no están sometidas a una regulación adecuada. La esterilización de la acumulación de reservas constituye una primera alternativa, pero la experiencia indica que podría verse derrotada por el arbitraje de intereses, si no existen restricciones a la entrada de capitales. Una segunda posibilidad sería el control directo de la expansión del crédito proporcionado por intermediarios financieros nacionales, pero en la práctica esta alternativa puede fomentar un mayor endeudamiento externo en ausencia de controles apropiados, y tiende a proteger a los intermediarios ineficientes. La tercera alternativa consistiría en imponer encajes o requisitos de liquidez a los pasivos del sistema financiero nacional, pero esto también puede alentar a los agentes no financieros a contraer préstamos en el extranjero.

La regulación a la entrada de capitales también podría ser esencial para evitar una apreciación insostenible del tipo de cambio en épocas de auge. Aunque un cierto grado de revaluación puede ser inevitable e incluso eficiente como mecanismo de absorción de la mayor oferta de divisas, una apreciación excesiva puede también tener efectos irreversibles asociados a la "enfermedad holandesa". La regulación de la entrada de capitales desempeña, por consiguiente, una función fundamental en economías en desarrollo abiertas, como mecanismo para permitir una restricción monetaria y del crédito interno y evitar una revaluación insostenible del tipo de cambio en períodos de auge. Lamentablemente, los efectos macroeconómicos de la regulación de la entrada de capitales han recibido mucha menos atención en el pasado que el tema de la regulación de la salida de capitales durante las crisis. La naturaleza de este tipo de regulación se analiza más adelante. En cualquier caso, la regulación a la salida de capitales también puede cumplir una función como mecanismo para evitar un alza excesiva de la tasa de interés o del tipo de cambio, que tiene los efectos adversos en la dinámica macroeconómica y puede aumentar el riesgo de que se produzcan crisis financieras nacionales. Dichas regulaciones son, además, un elemento esencial de las operaciones de suspensión de pagos y de renegociación ordenada de la deuda externa. Indudablemente, sólo puede usarse como complemento de un ajuste macroeconómico fundamental, en ningún caso como sustituto de éste.

Como se señala en la sección IV, en la regulación y supervisión prudencial habría que tomar en consideración tanto los riesgos microeconómicos como los riesgos macroeconómicos típicos de los países en desarrollo. En particular, convendría prestar la debida atención a los vínculos existentes entre los riesgos financieros internos y las variaciones de los principales instrumentos de política macroeconómica, sobre todo de las tasas de interés y el tipo de cambio. También habría que dar adecuada consideración a los riesgos que supone la acelerada expansión del crédito interno, a los descalces de monedas entre activos y pasivos, a la acumulación de deudas a corto plazo en divisas contraídas por intermediarios financieros y a la valorización de los activos fijos utilizados como garantía en episodios de inflación de activos. Dependiendo del tipo de operación, habría que adoptar requisitos más elevados de capital y disposiciones complementarias sobre liquidez, o imponer límites a la proporción del valor de los activos que se puede utilizar como garantía. Además, dada la existencia de estos vínculos macroeconómicos, en los períodos de euforia financiera se debería reforzar la regulación prudencial, para tener en cuenta los crecientes riesgos a los que se exponen los intermediarios financieros. Otra consecuencia de los vínculos mencionados es el hecho de que las políticas de contracción monetaria o crediticia que se adopten en los períodos de auge, como el establecimiento de encajes más elevados o la imposición de límites al 
crecimiento del crédito interno, podrían ser un excelente complemento de una regulación y supervisión prudencial más estricta. Por otra parte, debido a las importantes externalidades que pueden generar las grandes empresas no financieras sobre el sector financiero de un país, especialmente en casos de depreciación cambiara, la contracción de deudas externas por parte de dichas firmas también debería ser objeto de regulación. Algunos incentivos tributarios (la imposición de topes a las deducciones de pérdidas cambiarias, por ejemplo), o normas que obliguen a las empresas no financieras a informar públicamente sobre sus deudas externas pueden ser, por lo tanto, complementos relevantes de la regulación y supervisión prudencial adecuada de los intermediarios financieros.

La experiencia de muchos países en desarrollo indica que las crisis no están asociadas únicamente a elevados niveles de endeudamiento, sino también a perfiles inadecuados de la deuda. Esto obedece fundamentalmente al hecho de que, en un contexto de incertidumbre, los mercados financieros no responden sólo a las necesidades de financiamiento neto, sino también de financiamiento bruto, es decir, que la refinanciación de deudas de corto plazo no es neutral en términos financieros. Esta situación otorga un papel esencial a las "políticas de pasivos" destinadas a mejorar el perfil de la deuda. Aunque el principal objetivo de esas políticas debe ser el inducir un perfil de la deuda externa adecuado, hay una estrecha complementariedad entre un buen perfil de las deudas interna y externa. Así, el excesivo endeudamiento interno de corto plazo puede obligar a un gobierno interesado en refinanciar la deuda en medio de una crisis a elevar las tasas de interés, con el objeto de evitar la fuga de capitales de inversionistas en bonos públicos. Igualmente, el excesivo volumen de deudas privadas de corto plazo acentúa los riesgos percibidos por los prestamistas extranjeros en épocas de crisis, lo que puede conducir a una mayor contracción del endeudamiento externo.

En el caso del sector público, un instrumento adecuado de una política de deuda es la imposición de controles directos por parte del Ministerio de Hacienda. En el del sector privado, la flexibilidad del tipo de cambio también puede desalentar ciertos flujos de corto plazo y, por consiguiente, actuar en parte como una "política de pasivos", pero sus efectos son limitados en este ámbito, debido a la escasa probabilidad de que mitigue los ciclos de financiamiento de mediano plazo, que tenderán, por lo tanto, a reflejarse en un ciclo paralelo de los tipos de cambio nominal y real. La aplicación de controles directos a las entradas de ca- pitales también puede ser un buen instrumento para mejorar el perfil de deuda privada, pero un instrumento de mercado indirecto interesante son los encajes a las entradas de capital de origen externo, como lo indican las experiencias de Chile y Colombia en los años noventa. Estos encajes son una variedad del impuesto Tobin, pero la tasa impositiva equivalente $(3 \%$ en el caso de Chile para préstamos a un año y $10 \%$ o más en Colombia en épocas de auge) es mucho más alta que la que ha sido sugerida para un impuesto Tobin internacional. Un encaje uniforme mejora el perfil de la deuda, al inducir un endeudamiento de más largo plazo, que permite distribuir el impuesto equivalente a lo largo de un período más prolongado, y su administración es más fácil. Los efectos de este tipo de instrumentos sobre la magnitud de los flujos de capital han sido objeto de mayor controversia. En todo caso, si la elusión de la regulación es costosa, y si el endeudamiento de corto y largo plazo no son sustitutos perfectos, la magnitud de los flujos también debería verse afectada. ${ }^{32}$ Una de las principales ventajas de este instrumento es su focalización en la entrada de capitales, por lo que constituye una herramienta de carácter preventivo. También ofrece ventajas específicas en comparación con instrumentos de regulación prudencial que tengan efectos similares, puesto que afecta tanto a los agentes financieros como a los no financieros y supone el uso de un instrumento de precios no discriminatorio, mientras que la regulación prudencial sólo afecta a los intermediarios financieros, suele ser de carácter cuantitativo y la supervisión es un instrumento esencialmente discrecional. ${ }^{33}$

Las normas simples son preferibles a las complejas, sobre todo en sistemas regulatorios poco desarrollados. En este sentido, los controles cuantitativos, tales como la prohibición categórica de determinadas actividades u operaciones, pueden ser más convenientes que señales sofisticadas de precios, pero incentivos de precio simples, como los adoptados por Chile y Colombia, también pueden ser eficaces. Todo sistema regulatorio debe cumplir también con el requisito de contar con un respaldo institucional adecuado. Por consiguiente, un sistema permanente de regulación de

\footnotetext{
32 Agosin (1997), Agosin y Ffrench-Davis (por publicarse) y Ocampo y Tovar (1997 y 1999).

33 Ocampo (1999a). De hecho, este instrumento es similar a las prácticas empleadas por los agentes privados, como las comisiones impuestas por fondos mutuos a las inversiones que se han mantenido por períodos cortos, con el objeto de desalentarlas. Véase Morgan (1998, p. 23).
} 
la cuenta de capitales, cuyo grado de rigor se acentúe o se reduzca a lo largo del ciclo económico, es preferible a la alternación de libre entrada de capitales durante los períodos de auge y controles cuantitativos en épocas de crisis. De hecho, este último sistema puede ser enteramente ineficaz si se aplica en forma improvisada en una crisis; dado que carece de los mecanismos de administración necesarios, puede conducir a una evasión o elusión masivas de los controles. Un sistema de este tipo también se caracteriza por ser procíclico e ignora la lección más importante sobre prevención de crisis: la conveniencia de evitar el endeudamiento excesivo en épocas de auge y, por lo tanto, de centrar las regulaciones en las entradas en lugar de las salidas de capital.

Este análisis nos indica que la regulación de la cuenta de capitales puede ser un instrumento fundamental de prevención y manejo de crisis, en casos de gran volatilidad de los flujos de capital y debilidad de las redes internacionales de seguridad financiera. Las normas sobre la materia pueden ser complementarias de otras políticas aconsejables de regulación macroeconómica y financiera, y en algunos casos pueden ser incluso preferibles a otras alternativas. El análisis demuestra también la conveniencia de recurrir a la regulación de la cuenta de capitales como instrumento permanente de política. Obviamente, ninguno de estos mecanismos es perfecto, y algunos países en desarrollo pueden preferir combinaciones de políticas que eviten su uso (entre otras cosas, recurrir con más frecuencia a las políticas fiscales y cambiarias, así como a la regulación prudencial) o pueden inclinarse hacia un menor intervencionismo, aunque sea a expensas de una mayor volatilidad del PIB. Por este motivo, el argumento más convincente es aquel en favor del mantenimiento de la autonomía de los países en desarrollo en el manejo de la cuenta de capitales.

En realidad, no hay razones convincentes que permitan abogar por la convertibilidad de la cuenta de capitales. ${ }^{34}$ No existen pruebas de que la movilidad del capitales permita suavizar el gasto en los países en desarrollo a lo largo del ciclo económico y, por el contrario, hay evidencias categóricas de que la volatilidad de los flujos de capital en esos países es una fuente

\footnotetext{
${ }^{34}$ Véase análisis más detallados sobre este tema en Naciones Unidas, Grupo de Trabajo del Comité Ejecutivo de Asuntos Económicos y Sociales (1999a); UNCTAD (1998, parte I, cap. IV), CEPAL (1998a, parte III), Eichengreen (1999), Griffith-Jones (1998), Grilli y MilesiFerreti (1995), Krugman (1998a, 1998b), Ocampo (1999a) y Rodrik (1998).
}

adicional de inestabilidad del gasto. Tampoco hay nada que demuestre la existencia de un vínculo entre la liberalización de la cuenta de capitales y el crecimiento económico, pero sí argumentos que demuestran lo contrario. ${ }^{35}$ Para expresar este argumento en términos sencillos, se podría decir que, aun si la mayor libertad de los flujos de capital influye positivamente sobre el crecimiento, a través de una asignación más eficiente del ahorro y la inversión, la mayor volatilidad que caracteriza a los mercados libres de capital tiene el efecto contrario. Como ya se ha señalado, la falta de una red de seguridad financiera internacional adecuada también es un argumento convincente en este sentido. ¿Por qué deberían renunciar los países en desarrollo a este grado de libertad si no tienen acceso a un financiamiento para contingencias que sea adecuado en cuanto a su volumen y normas bien definidas de condicionalidad, y no existen actualmente mecanismos que faciliten la suspensión de pagos con anuencia internacional y la renegociación ordenada de la deuda? Como se indica en la sección III, esto es esencial para los países sin mayor poder en el ámbito internacional, para los cuales el renunciar a algún mecanismo para hacer frente a las crisis es una alternativa que tiene un costo elevado. En realidad, hay notables semejanzas entre la actual situación financiera internacional y las etapas de banca libre a nivel nacional, cuando, en ausencia de bancos centrales que operaran como prestamistas de última instancia y de programas oficiales de rescates bancarios, la inconvertibilidad de los billetes emitidos por los bancos privados era una alternativa legal necesaria para responder a corridas de fondos masivas.

Utilizando argumentos muy similares, se podría afirmar que sería igualmente inadecuado limitar la autonomía de los países en desarrollo para elegir un determinado régimen cambiario. Aunque tiene cierta validez el argumento según el cual, en el mundo globalizado de hoy, sólo las cajas de convertibilidad o los tipos de cambio totalmente flexibles generan suficiente confianza en los agentes privados, cualquier norma internacional en este ámbito sería desafortunada. Las ventajas y desventajas de ambos extremos, y las de los regímenes intervencionistas intermedios, han sido objeto de un prolongado debate $\mathrm{y}$, por supuesto, han dado lugar a la acumulación de gran experiencia al respecto. En la práctica, los países casi siempre optan por regímenes intermedios, lo que responde no sólo a

\footnotetext{
35 Véase, en particular, Eatwell (1996), Rodrik (1998) y, con respecto a América Latina, Ocampo (1999b).
} 
las deficiencias que presentan los extremos, sino también a las numerosas otras demandas que enfrentan las autoridades. No obstante, la elección del régimen cambiario tiene importantes consecuencias en materia de política económica, que deben tenerse presentes en la

\section{IX}

\section{Conclusiones}

En este ensayo se ha argumentado que la agenda en torno a la reforma financiera internacional debería ampliarse por lo menos en dos sentidos. En primer término, debería extenderse más allá del ámbito de la prevención y solución de crisis, temas en los que se ha centrado el debate reciente, para incluir también materias tales como el financiamiento del desarrollo de países pobres y pequeños, a fin de superar la excesiva concentración del financiamiento privado y oficial en unas pocas economías "emergentes", y la "propiedad" de las políticas económicas por parte de los países. En segundo lugar, debería tener en cuenta no sólo el papel de las instituciones mundiales, sino también de las regionales, y la definición explícita de las áreas en que convendría preservar la autonomía nacional. Todos estos temas deberían hacer parte de un proceso de negociación representativo y equilibrado, capaz de superar algunos de los elementos negativos, vinculados a la economía política, que caracterizan el debate actual.

En lo que respecta a la prevención y solución de crisis financieras, debe encontrarse un equilibrio entre el énfasis que se ha otorgado en el debate actual a la necesidad de perfeccionar el marco institucional en el que operan los mercados financieros, y la insuficiente atención que siguen recibiendo el diseño de estructuras adecuadas que garanticen la coherencia de las políticas macroeconómicas a nivel mundial, la mayor provisión de financiamiento de emergencia en épocas de crisis, y la adopción de procedimientos adecuados de suspensión de pagos con anuencia internacional y de renegociación ordenada de la deuda. En el ámbito del financiamiento del desarrollo, debe otorgarse particular importancia a la necesidad de incrementar el financiamiento destinado a países de bajos ingresos, incluyendo los mecanismos que permitan que las agencias financieras multilaterales faciliten el mayor acceso de éstos y de los países pequeños de medianos ingresos a los mercados privados de capital. También supervisión macroeconómica. Además, según también hemos señalado, la regulación prudencial interna debe tomar en consideración los riesgos macroeconómicos específicos a los que se enfrentan los intermediarios financieros en cada régimen.

debe hacerse hincapié en la contribución de los bancos multilaterales de desarrollo al financiamiento de redes de protección social en períodos de crisis. La provisión de un mayor financiamiento de emergencia y con fines de desarrollo debería complementarse con un nuevo acuerdo internacional sobre los límites de la condicionalidad, y el pleno reconocimiento del papel esencial de la "propiedad" de las políticas macroeconómicas y de desarrollo por parte de los países en desarrollo.

Se ha argumentado igualmente que las instituciones regionales y subregionales deberían desempeñar un papel fundamental en la mayor provisión de "bienes públicos globales" y otros servicios en el área de las finanzas internacionales. En ciertos casos, la arquitectura financiera requerida debería consistir en una red de instituciones que presten los servicios necesarios en forma complementaria (en esferas tales como el financiamiento de emergencia, la supervisión de las políticas macroeconómicas, y la regulación y supervisión prudencial de los sistemas financieros nacionales), mientras en otros, sobre todo en la esfera del financiamiento del desarrollo, es preferible un sistema de organizaciones competitivas. El hecho de que todo nuevo orden seguirá siendo una "red de seguridad financiera" incompleta significa no sólo que las políticas nacionales seguirán ejerciendo un papel desproporcionado en la prevención de crisis, sino también que ciertas áreas deberían seguir siendo del dominio exclusivo de la autonomía nacional, en particular la regulación de la cuenta de capitales y la elección del régimen cambiario. Las instituciones regionales y la autonomía nacional son particularmente importantes para los participantes menos influyentes en el ámbito internacional, quienes se beneficiarían notablemente de la competencia en la provisión de los servicios que se les prestan y de contar con mayor libertad de acción en un contexto de oferta imperfecta de bienes públicos globales. 


\section{Bibliografía}

Agosin, M. (1997): Entradas de capitales y desempeño de la inversión: Chile en los años noventa, Flujos de capital e inversión productiva: lecciones para América Latina, Ricardo FfrenchDavis y Helmut Reisen (comps.), Santiago de Chile, McGraw Hill.

Agosin, M. y R. Ffrench-Davis (por publicarse): Managing capital inflows in Chile, Short-Term Capital Flows and Economic Crises, Stephany Griffith-Jones, Manuel F. Montes y Anwar Nasution (comps.), Nueva York, Oxford University Press/ Universidad de las Naciones Unidas (UNU)/Instituto Mundial de Investigaciones de Economía del Desarrollo (WIDER).

Akyüz, Y. y A. Cornford (1999): Capital flows to developing countries and the reform of the international financial system", documento presentado en la Reunión sobre nuevos roles y funciones de las Naciones Unidas y las instituciones de Bretton Woods, organizada por la Universidad de las Naciones Unidas y el Instituto Mundial de Investigaciones de Economía del Desarrollo (WIDER).

Banco Mundial (1999): Global Development Finance, 1999, Washington, D.C., marzo.

(1998a): Global Economic Prospects and the Developing Countries, 1998-99, Washington, D.C., diciembre.

(1998b): Assessing Aid, World Bank Policy Research Report, Nueva York, Oxford University Press, noviembre.

Calvo, G. (1998), Contagion and sudden stops, Baltimore, Maryland, Univerisidad de Maryland, noviembre, inédito.

Camdessus, M. (1998a): Discurso inaugural pronunciado ante la Junta de Gobernadores del FMI, Boletín del FMI, vol. 27, № 19, Fondo Monetario Internacional (FMI), 26 de octubre.

(1998b): Towards an agenda for international monetary and financial reform, Address to the World Affairs Council, Filadelfia, Pennsylvania, 6 de noviembre.

CEPAL (Comisión Económica para América Latina y el Caribe) (1998a): América Latina y el Caribe: políticas para mejorar la inserción en la economía mundial, $2^{\mathrm{a}}$ edición revisada y actualizada, Santiago de Chile, Fondo de Cultura Económica.

(1998b): El pacto fiscal: fortalezas, debilidades, desafios, LC/G.1997/Rev.1, Santiago de Chile, abril.

(1998c): La crisis financiera internacional: una visión desde la CEPAL, LC/G.2040, Santiago de Chile, octubre.

Cornia, G. A. (1999): Social Funds in Stabilization and Adjustment Programmes, Research for Action, $\mathrm{N}^{\mathrm{o}} 48$, Helsinski, Universidad de las Naciones Unidas (UNU)/Instituto Mundial de Investigaciones de Economía del Desarrollo (WIDER), abril.

Eatwell, J. (1996): International Financial Liberalization: The Impact on World Development, UNDP-Office of Development Studies Discussion Paper, No 12 , Nueva York, Programa de las Naciones Unidas para el Desarrollo (PNUD), septiembre.

Eatwell, J. y L. Taylor (1999): Global Finance at Risk: The Case for International Regulation, New School for Social Research and Cambridge University.

Eichengreen, B. (1999): Towards a New International Financial Architecture: A Practical Post-Asia Agenda, Washington, D.C., Instituto de Economía Internacional (IIE).

(1998): The only game in town, Berkeley, California, Universidad de California, noviembre, inédito.

Feldstein, M. (1998): Refocusing the IMF, Foreign Affairs, vol. 77, $\mathrm{N}^{\circ}$ 2, Nueva York, marzo/abril.

Ffrench-Davis, R. (1999): Reforming the Reforms in Latin America: Macroeconomics, Trade, Finance, Londres, Macmillan, en prensa.

FMI (Fondo Monetario Internacional) (1998): Toward a Framework for Financial Stability, Washington, D.C., enero.

FMI, Comité Provisional de la Junta de Gobernadores sobre el Sistema Monetario Internacional (1998): Statement, Washington, D.C., Fondo Monetario Internacional (FMI), 16 de abril.
Graham, C. (1994), Safety Nets, Politics, and the Poor, Washington, D.C., The Brookings Institution.

Griffith-Jones, S. (1998): Global Capital Flows, Should They Be Regulated?, Londres, Macmillan.

Griffith-Jones, S. y J. A. Ocampo (1999): Proposals for a new international architecture, with special emphasis on needs of poorer countries, informe presentado al Ministerio de Relaciones Exteriores de Suecia, junio.

Grilli, V. y G. M. Milesi-Ferretti (1995): Economic Effects and Structural Determinants of Capital Controls, IMF Staff Papers, vol. $42, \mathrm{~N}^{\mathrm{o}} 3$, septiembre.

Grupo de los 24 (1999): Communiqué, 25 de septiembre.

(1998), Communiqué, 3 de octubre.

Grupo de los Siete (1999): Statement, Colonia, 18 de junio.

(1998): Declaration of G-7 Finance Ministers and Central Bank Governors, 30 de octubre.

Helleiner, G. K. (1999a): Financial markets, crises and contagion: issues for smaller countries in the FTAA and Post-Lomé IV negotiations, documento preparado para el Mecanismo de negociación regional del Caribe, Kingston, Jamaica, enero.

(1999b): External conditionality, local ownership and development, contribución a Transforming Development, Jim Freedman (comp.), Toronto, University of Toronto Press.

(1997): Capital account regimes and the developing countries, International Monetary and Financial Issues for the 1990s, vol. 8, Nueva York, Conferencia de las Naciones Unidas sobre Comercio y Desarrollo (UNCTAD).

Helleiner, G. K. y A. Oyejide (1998): Global economic governance, global negotiations and the developing countries, documento de antecedentes para PNUD, Informe sobre desarrollo humano, 1999, diciembre.

Krugman, P. (1998a): The Eternal Triangle, Cambridge, Massachusetts, Instituto de Tecnología de Massachusetts (MIT), inédito.

(1998b): Curfews on capital flight: What are the options?, Cambridge, Instituto de Tecnología de Massachusetts (MIT), inédito.

Larraín, G., H. Reisen y J. von Maltzan (1997): Emerging Market Risk and Sovereign Credit Ratings, OCDE Development Centre Technical Paper, $N^{\circ}$ 124, París, Organización de Cooperación y Desarrollo Económicos (OCDE), abril.

Lustig, N. (1997): The safety nets which are not safety nets: Social investment funds in Latin America, documento preparado para la Conferencia sobre gobernabilidad, erradicación de la pobreza y política social, organizada por el Harvard Institute for Institutional Development y el Programa de las Naciones Unidas para el Desarrollo (PNUD), y realizada en Cambridge, Massachusetts, Universidad de Harvard, 12 y 13 de noviembre.

Márquez, G. (1999): Labor markets and income support: What did we learn from the crises?, Washington, D.C., Banco Interamericano de Desarrollo (BID), inédito.

Miyazawa, K. (1998): Towards a new international financial architecture, presentación ante el Foreign Correspondents Club of Japan, 15 de diciembre.

Mohammed, A. A. (1999): Adequacy of liquidity in the current international financial environment, Studies on International Monetary and Financial Issues for the Group of Twenty-Four, Grupo Intergubernamental de los Veinticuatro para Asuntos Monetarios Internacionales, abril

Morgan J. P. (1998): World Financial Markets, Nueva York, 7 de octubre.

Naciones Unidas, Grupo de Trabajo del Comité Ejecutivo de Asuntos Económicos y Sociales (1999a): Hacia una nueva arquitectura financiera internacional. Informe del Grupo de Trabajo del Comité Ejecutivo de Asuntos Económicos y Sociales 
de las Naciones Unidas LC/G.2054, Santiago de Chile, Comisión Económica para América Latina y el Caribe (CEPAL), marzo.

(1999b): Finding Solutions to the Debt Problems of Developing Countries, serie Temas de coyuntura, $\mathrm{N}^{\circ} 2$, LC/L.1230-P, Santiago de Chile, mayo. Publicación de las Naciones Unidas, $\mathrm{N}^{\mathrm{o}}$ de venta: E.99.II.G.5.

Ocampo, José Antonio (1999a): Reforming the International Financial Architecture: Consensus and Divergence, serie Temas de coyuntura, $N^{\circ} 1$, LC/L.1192, Santiago de Chile, Comisión Económica para América Latina y el Caribe (CEPAL), abril. Publicación de las Naciones Unidas, $\mathrm{N}^{\circ}$ de venta: E.99.II.G.6.

(1999b): La reforma de un sistema financiero internacional: un debate en marcha, Santiago de Chile, Fondo de Cultura Económica/Comisión Económica para América Latina y el Caribe (CEPAL).

Ocampo, J. A. y C. Tovar (1999): Price-Based Capital Account Regulations: The Colombian Experience, serie Financiamiento del desarrollo, $N^{\circ}$ 87, LC/L.1262-P, Santiago de Chile.

(1997): Flujos de capital, ahorro e inversión en Colombia, 1990-1996, Flujos de capital e inversión productiva: lecciones para América Latina, Ricardo Ffrench-Davis y Helmut Reisen (comps.), Santiago de Chile, Comisión Económica para América Latina y el Caribe (CEPAL)/Centro de Desarrollo, Organización de Cooperación y Desarrollo Económicos (OCDE), McGraw-Hill.

Rodrik, D. (1999a): The New Global Economy and Developing Countries: Making Openness Work, Policy Essay, $\mathrm{N}^{\mathrm{o}} 24$, Washington, D.C., Consejo de Desarrollo de Ultramar.

(1999b), Governing the global economy: Does one architectural style fit all?, documento preparado para la Con- ferencia sobre métodos de gobierno en una economía mundial, organizada por el Foro sobre políticas de comercio de la Brookings Institution, 15 y 16 de abril.

(1998): Who needs capital-account convertibility? Essays in International Finance, $\mathrm{N}^{\mathrm{o}}$ 207, Princeton, Departamento de Economía, Universidad de Princeton.

(1997): Has Globalization Gone Too Far?, Washington, D.C., Instituto de Economía Internacional (IIE).

Rubin, R. E. (1999): Remarks of the Treasury Secretary on reform of the international financial architecture to the School of Advanced International Studies, Treasury News, Oficina de Asuntos Públicos, 21 de abril.

UNCTAD (Conferencia de las Naciones Unidas sobre Comercio y Desarrollo) (1999), Informe sobre el comercio y desarrollo, 1999, UNCTAD/TDR/1999, Ginebra.

(1998): Informe sobre el comercio y desarrollo, 1998, UNCTAD/TDR/1998, Ginebra. Publicación de las Naciones Unidas, $\mathrm{N}^{\circ}$ de venta: S.98.II.D.6.

White, W. R. (1999): New strategies for dealing with the instability of financial markets, documento presentado en la conferencia sobre "La gestión de los mercados financieros mundiales: desafíos y opciones de políticas para las economías emergentes, la Unión Europea y las instituciones internacionales", organizada por el Foro sobre deuda y desarrollo y realizada en el Banco Nacional de Hungría, Budapest, 24 y 25 de junio.

Wolfensohn, J. D. (1998): The other crisis, Address to the Board of Governors, Washington, D.C., 6 de octubre.

Wyplosz, Ch. (1999): International financial instability, Global Public Goods: International Cooperation in the $21^{\text {st }}$ Century, Inge Kaul, Isabelle Grunberg y Marc A. Stern (comps.), Nueva York, Programa de las Naciones Unidas para el Desarrollo (PNUD), Oxford University Press. 